\title{
Acceleration of 1,3-Dipolar Cycloadditions by Integration of Strain and Electronic Tuning
}

Jesús M. Dones, Nile S. Abularrage, Namrata Khanal, Brian Gold,* and Ronald T. Raines*

Department of Chemistry, Massachusetts Institute of Technology, Cambridge, Massachusetts 02139, United States, and Department of Chemistry and Chemical Biology, University of New Mexico, Albuquerque, New Mexico 87131, United States

*Email: bgold1@unm.edu and rtraines@mit.edu

\begin{tabular}{ll}
\hline \multicolumn{1}{c}{ Content } & Page \\
\hline Table of Contents & $\mathrm{S} 1$ \\
List of Abbreviations & $\mathrm{S} 2$ \\
Computational Details and Data (Tables S1-S4 and Figures S1-S6) & $\mathrm{S} 3$ \\
Figure S7. Stability of DIBAC and ABC & $\mathrm{S} 12$ \\
Experimental Procedures & $\mathrm{S} 13$ \\
Kinetic Analyses & $\mathrm{S} 17$ \\
Cyclooctyne Stability Experiments & $\mathrm{S} 18$ \\
Kinetic Traces & $\mathrm{S} 19$ \\
References & $\mathrm{S} 21$ \\
NMR Spectra & $\mathrm{S} 22$ \\
\hline
\end{tabular}




\section{List of Abbreviations}

$\begin{array}{ll}\text { ABC } & \text { 2-azabenzo-8-chlorobenzocyclootyne } \\ \text { ACN } & \text { acetonitrile } \\ \text { CPCM } & \text { conductor-like polarizable continuum model } \\ \text { DIBAC } & \text { dibenzoazacyclooctyne } \\ \text { DIBO } & \text { dibenzocyclooctyne } \\ \text { DIC } & N, N^{\prime} \text {-diisopropylcarbodiimide } \\ \text { DIFO } & \text { difluorocyclooctyne } \\ \text { diF-SNO-OCT } & \text { difluoro-sulfur, nitrogen, and oxygen-containing heterocyclic cyclooctyne } \\ \text { DMSO } & \text { dimethyl sulfoxide } \\ \text { EDC } & \text { 1-ethyl-3-(3-dimethylaminopropyl)carbodiimide } \\ \text { HPLC } & \text { high-performance liquid chromatography } \\ \text { IEFPCM } & \text { integral equation formalism of the polarizable continuum model } \\ \text { LiHMDS } & \text { lithium bis(trimethylsilyl)amide } \\ \text { NBO } & \text { natural bonding orbital } \\ n \text {-ABC } & n \text {-azabenzo-benzocyclooctyne ( } n=2-6) \\ \text { OCT } & \text { cyclooctyne } \\ \text { PBS } & \text { phosphate-buffered saline } \\ \text { PNBO } & \text { pre-orthogonal natural bonding orbital } \\ \text { SPAAC } & \text { strain-promoted azide-alkyne cycloaddition } \\ \text { TFA } & \text { trifluoroacetic acid } \\ \text { THF } & \text { tetrahydrofuran } \\ \text { TS } & \text { transition state } \\ \text { UFF } & \text { universal force field } \\ & \end{array}$


Computational Details. Geometry optimizations were performed with Gaussian 16 software $^{\mathrm{S} 1}$ at the M06-2X level of theory ${ }^{\mathrm{S} 2}$ (including the IEFPCM dielectric continuum solvent model for either $\mathrm{CH}_{2} \mathrm{Cl}_{2}$ or water, with $\mathrm{UFF}$ radii $\left.{ }^{\mathrm{S} 3}\right)$ or the $\mathrm{B} 97 \mathrm{D} / 6-311+\mathrm{G}(\mathrm{d}, \mathrm{p})$ level of theory ${ }^{\mathrm{S} 3}$ (including the CPCM solvation model for either $\mathrm{CH}_{2} \mathrm{Cl}_{2}$ or water ${ }^{\mathrm{S}}, \mathrm{S} 5$ ). Frequency calculations were performed to confirm stationary points as minima or first-order saddle points. All $\Delta E$ and $\Delta E^{*}$ values include zero-point corrections. For previous reports benchmarking the methods utilized, see ref. S6 and S7. Coordinates, total energies, and imaginary frequencies (transition states) are provided in the XYZ files.

Conformational Search. Manual conformational searches were performed at both levels of theory employing the specified solvation models for water. Low energy structures were reoptimized in dichloromethane. For simplicity and brevity, tables contain the activation energies and free energies corresponding to located minima which display the most favorable free energy of activation. Figures S1 and S2 contain representative, low lying transition states located for 2$\mathrm{ABC}$ and $\mathrm{ABC}$.

Starting Materials. In all cyclooctynes (other than DIBAC), rotation about the ethylene bridge gives an enantiomer. For DIBAC, nitrogen inversion was considered. For diazoacetamides, the $s$-cis and $s$-trans conformers of the diazo group relative to the carbonyl were optimized. For azidoacetamides, rotation about the $\psi\left(\mathrm{NC}-\mathrm{C}_{\alpha} \mathrm{N}_{3}\right.$ dihedral $)$ and $\phi\left(\mathrm{CC}_{\alpha}-\mathrm{NN}_{2}\right)$ dihedral angles were examined via input geometries that varied in $60^{\circ}$ increments. These input geometries converged on 2-3 structures, dependent upon the level of theory and solvation model, that were within $\sim 0.5-2.0 \mathrm{kcal} / \mathrm{mol}$.

a-Azidoacetamide Transition States. Modes of approach considered the $\psi$ and $\phi$ dihedral angles described above and rotation about the dihedral angle of the azido group $\left(\mathrm{NN}-\mathrm{NC} \mathrm{C}_{\alpha}\right)$. The cyclooctyne ring limits the latter to a potential range of $\sim 180^{\circ}$ in the TS. For nonsymmetric cyclooctynes (DIBAC and ABCs) both the syn-and anti-approach of the 1,3-dipole substituents relative to the aza-/azabenzo-ring were considered. For DIBAC, all of the above was considered, along with nitrogen inversion. Low energy transition states are included.

a-Diazoacetamide Transition States. Modes of approach were chosen as input geometries for each diazoacetamide conformation (i.e., the s-cis and s-trans conformers). Low energy transition states are included. 
Table S1. Energies and free energies of activation $(\mathrm{kcal} / \mathrm{mol})$ for cycloadditions of 2-azido- $N$ methylacetamide (1) and 2-diazo- $N$-methylacetamide (2) with constitutional isomers of dibenzoazacyclooctyne (DIBAC). Geometries were optimized at both M06-2X/6$311++\mathrm{G}(\mathrm{d}, \mathrm{p})$ employing the IEFPCM solvation model and B97D/6-311+G(d,p) employing the $\mathrm{CPCM}$ solvation model for either $\mathrm{CH}_{2} \mathrm{Cl}_{2}$ or water. ${ }^{a}$ Energies for the preferred regioisomer are in bold typeface.

\begin{tabular}{|c|c|c|c|c|c|c|c|c|c|c|}
\hline \multirow{3}{*}{ Method } & \multirow{3}{*}{ Solvent } & \multirow{3}{*}{ Compound } & \multicolumn{4}{|c|}{ Azide 1} & \multicolumn{4}{|c|}{ Diazo Compound 2} \\
\hline & & & \multicolumn{2}{|c|}{ syn TS } & \multicolumn{2}{|c|}{ anti TS } & \multicolumn{2}{|c|}{ syn TS } & \multicolumn{2}{|c|}{ anti TS } \\
\hline & & & $\Delta E^{+}$ & $\Delta G^{\ddagger}$ & $\Delta E^{\ddagger}$ & $\Delta G^{\ddagger}$ & $\Delta E^{+}$ & $\Delta G^{\ddagger}$ & $\Delta E^{+}$ & $\Delta G^{\ddagger}$ \\
\hline \multirow[t]{7}{*}{ M06-2X } & $\mathrm{CH}_{2} \mathrm{Cl}_{2}$ & DIBO & 9.6 & 23.5 & - & $\overline{-}$ & 10.6 & 23.7 & - & - \\
\hline & & DIBAC & 8.9 & 22.2 & 8.9 & 22.4 & 10.1 & 23.2 & 8.8 & 21.6 \\
\hline & & $2-A B C$ & 6.1 & 19.5 & 10.4 & 23.9 & 5.5 & 18.8 & 10.7 & 23.7 \\
\hline & & $3-A B C$ & 9.8 & 23.0 & 9.5 & 23.1 & 9.9 & 22.9 & 9.8 & 22.7 \\
\hline & & $4-A B C$ & 9.5 & 22.2 & 9.5 & 23.0 & 10.0 & 22.9 & 9.7 & 22.5 \\
\hline & & $5-A B C$ & 9.8 & 22.7 & 9.6 & 23.1 & 10.5 & 23.2 & 9.7 & 21.1 \\
\hline & & $6-A B C$ & 8.6 & 22.5 & 7.5 & 21.0 & 7.0 & 20.7 & 6.1 & 19.3 \\
\hline \multirow[t]{7}{*}{ M06-2X } & $\mathrm{H}_{2} \mathrm{O}$ & DIBO & 10.3 & 23.7 & - & - & 10.6 & 23.7 & - & - \\
\hline & & DIBAC & 9.6 & 23.3 & 9.1 & 22.9 & 10.1 & 23.3 & 8.9 & 22.1 \\
\hline & & $2-A B C$ & 8.3 & 21.9 & 10.5 & 23.8 & 6.2 & 19.5 & 10.6 & 23.7 \\
\hline & & $3-A B C$ & 10.0 & 23.5 & 9.7 & 23.2 & 10.0 & 22.8 & 9.8 & 22.8 \\
\hline & & $4-A B C$ & 9.8 & 23.3 & 9.6 & 22.9 & 9.9 & 22.7 & 9.8 & 22.9 \\
\hline & & $5-A B C$ & 10.1 & 23.5 & 9.7 & 23.1 & 10.3 & 23.2 & 10.0 & 23.2 \\
\hline & & $6-A B C$ & 8.6 & 22.1 & 7.7 & 21.3 & 7.1 & 20.5 & 6.8 & 19.7 \\
\hline \multirow[t]{7}{*}{ B97D } & $\mathrm{CH}_{2} \mathrm{Cl}_{2}$ & DIBO & 5.2 & 19.6 & - & - & 7.8 & 20.9 & - & - \\
\hline & & DIBAC & 4.7 & 18.9 & 5.5 & 18.5 & 6.9 & 20.3 & 6.0 & 19.3 \\
\hline & & $2-A B C$ & 3.9 & 18.2 & 6.2 & 20.4 & 3.6 & 17.3 & 8.3 & 21.7 \\
\hline & & $3-A B C$ & 5.0 & 19.2 & 4.8 & 19.2 & 7.0 & 20.0 & 7.0 & 20.2 \\
\hline & & $4-A B C$ & 5.2 & 19.5 & 4.8 & 19.2 & 7.2 & 20.2 & 7.1 & 20.3 \\
\hline & & $5-A B C$ & 5.2 & 19.6 & 4.9 & 19.4 & 7.7 & 20.7 & 7.2 & 20.3 \\
\hline & & $6-A B C$ & 5.3 & 19.3 & 4.9 & 18.7 & 4.6 & 17.8 & 4.0 & 16.9 \\
\hline \multirow[t]{7}{*}{ B97D } & $\mathrm{H}_{2} \mathrm{O}$ & DIBO & 5.5 & 18.9 & - & - & 7.9 & 20.9 & - & - \\
\hline & & DIBAC & 5.2 & 18.2 & 5.8 & 17.9 & 7.1 & 20.4 & 6.2 & 19.4 \\
\hline & & $2-A B C$ & 4.3 & 17.5 & 6.4 & 19.8 & 4.1 & 17.8 & 8.4 & 21.6 \\
\hline & & $3-A B C$ & 5.4 & 18.6 & 5.1 & 18.4 & 7.4 & 20.4 & 7.1 & 20.1 \\
\hline & & 4-ABC & 5.5 & 18.7 & 5.1 & 18.4 & 7.2 & 20.1 & 7.2 & 20.4 \\
\hline & & $5-A B C$ & 5.6 & 18.8 & 5.3 & 18.6 & 7.7 & 20.1 & 7.4 & 20.4 \\
\hline & & $6-A B C$ & 5.3 & 18.6 & 5.3 & 18.0 & 4.8 & 17.8 & 4.6 & 17.5 \\
\hline
\end{tabular}

${ }^{a}$ Energies given for conformers favored by $\Delta G^{\ddagger}$. See Figure $\mathrm{S} 1$ and the computational details. 
Table S2. Distortion/Interaction (Activation-Strain) analysis of energies ( $\mathrm{kcal} / \mathrm{mol}$ ) for cycloadditions of 2-azido- $N$-methylacetamide (1) with constitutional isomers of dibenzoazacyclooctyne (DIBAC). Geometries optimized at both M06-2X/6-311++G(d,p) employing the IEFPCM solvation model for either $\mathrm{CH}_{2} \mathrm{Cl}_{2}$ or water, and B97D/6-311+G(d,p) employing the CPCM solvation model for either $\mathrm{CH}_{2} \mathrm{Cl}_{2}$ or water. Energies for the preferred regioisomer are in bold typeface.

\begin{tabular}{|c|c|c|c|c|c|c|c|c|c|c|}
\hline \multirow{3}{*}{ Method } & \multirow{3}{*}{ Solvent } & \multirow{3}{*}{ Compound } & \multicolumn{4}{|c|}{ syn TS } & \multicolumn{4}{|c|}{ anti TS } \\
\hline & & & \multicolumn{3}{|c|}{$\Delta E^{\ddagger}$ distortion } & \multirow{2}{*}{$\Delta E^{\ddagger}{ }_{\text {Interaction }}$} & \multicolumn{3}{|c|}{$\Delta E^{\ddagger}$ distortion } & \multirow{2}{*}{$\Delta E^{\ddagger}{ }_{\text {Interaction }}$} \\
\hline & & & 1,3-Dipole & Alkyne & Total & & 1,3-Dipole & Alkyne & Total & \\
\hline \multirow[t]{7}{*}{ M06-2X } & $\mathrm{CH}_{2} \mathrm{Cl}_{2}$ & DIBO & 18.6 & 3.2 & 21.8 & -12.1 & - & - & - & - \\
\hline & & DIBAC & 18.3 & 3.0 & 21.3 & -12.5 & 16.1 & 2.5 & 18.6 & -9.7 \\
\hline & & $2-A B C$ & 16.7 & 2.6 & 19.3 & -13.2 & 16.2 & 2.4 & 18.7 & -10.9 \\
\hline & & $3-A B C$ & 16.7 & 2.9 & 19.6 & -9.9 & 16.7 & 2.9 & 19.6 & -10.1 \\
\hline & & $4-A B C$ & 16.8 & 3.0 & 19.8 & -10.3 & 16.7 & 2.9 & 19.6 & -10.2 \\
\hline & & $5-A B C$ & 17.0 & 3.0 & 20.0 & -10.2 & 16.8 & 2.9 & 19.7 & -10.1 \\
\hline & & $6-A B C$ & 16.7 & 3.7 & 20.4 & -11.8 & 16.0 & 3.8 & 19.7 & -12.2 \\
\hline \multirow[t]{7}{*}{ M06-2X } & $\mathrm{H}_{2} \mathrm{O}$ & DIBO & 17.0 & 3.0 & 20.1 & -9.8 & - & - & - & - \\
\hline & & DIBAC & 18.3 & 3.1 & 22.1 & -11.8 & 16.1 & 2.6 & 18.7 & -9.5 \\
\hline & & $2-A B C$ & 16.6 & 2.6 & 19.2 & -10.9 & 16.8 & 3.0 & 19.8 & -9.3 \\
\hline & & $3-A B C$ & 16.7 & 3.0 & 19.7 & -9.7 & 16.6 & 3.0 & 19.6 & -9.9 \\
\hline & & $4-A B C$ & 16.7 & 3.1 & 19.8 & -10.0 & 16.7 & 2.9 & 19.6 & -10.0 \\
\hline & & $5-A B C$ & 16.9 & 3.0 & 19.9 & -9.8 & 16.8 & 2.9 & 19.7 & -10.0 \\
\hline & & $6-A B C$ & 16.5 & 3.6 & 20.1 & -11.5 & 15.9 & 3.7 & 19.6 & -11.9 \\
\hline \multirow[t]{7}{*}{ B97D } & $\mathrm{CH}_{2} \mathrm{Cl}_{2}$ & DIBO & 16.3 & 3.0 & 19.4 & -14.2 & - & - & - & - \\
\hline & & DIBAC & 16.2 & 2.9 & 19.1 & -14.4 & 13.7 & 2.2 & 15.9 & -10.4 \\
\hline & & $2-A B C$ & 17.1 & 3.3 & 20.5 & -16.6 & 16.0 & 3.1 & 19.1 & -13.0 \\
\hline & & $3-A B C$ & 16.0 & 3.0 & 19.0 & -14.0 & 15.8 & 3.0 & 18.8 & -14.0 \\
\hline & & $4-A B C$ & 16.0 & 3.2 & 19.1 & -13.9 & 15.9 & 2.9 & 18.8 & -13.9 \\
\hline & & $5-A B C$ & 16.2 & 3.0 & 19.2 & -14.0 & 16.1 & 2.9 & 19.0 & -14.1 \\
\hline & & $6-A B C$ & 15.4 & 3.9 & 19.2 & -13.5 & 14.0 & 3.6 & 17.5 & -12.6 \\
\hline \multirow[t]{7}{*}{ B97D } & $\mathrm{H}_{2} \mathrm{O}$ & DIBO & 16.4 & 3.0 & 19.4 & -13.9 & - & - & - & - \\
\hline & & DIBAC & 16.3 & 2.9 & 19.2 & -14.0 & 13.9 & 2.2 & 16.1 & -10.3 \\
\hline & & $2-A B C$ & 17.1 & 3.3 & 20.4 & -16.1 & 16.1 & 3.1 & 19.2 & -12.8 \\
\hline & & $3-A B C$ & 16.1 & 3.0 & 19.1 & -13.7 & 15.9 & 2.9 & 18.8 & -13.8 \\
\hline & & $4-A B C$ & 16.1 & 3.2 & 19.3 & -13.8 & 16.0 & 2.9 & 18.9 & -13.7 \\
\hline & & $5-A B C$ & 16.3 & 3.0 & 19.3 & -13.8 & 16.2 & 2.9 & 19.1 & -13.9 \\
\hline & & $6-A B C$ & 15.5 & 3.8 & 19.3 & -14.0 & 14.1 & 3.5 & 17.6 & -12.3 \\
\hline
\end{tabular}


Table S3. Distortion/Interaction (Activation-Strain) analysis of energies $(\mathrm{kcal} / \mathrm{mol})$ for cycloadditions of 2-diazo- $N$-methylacetamide (2) with constitutional isomers of dibenzoazacyclooctyne (DIBAC). Geometries optimized at both M06-2X/6-311++G(d,p) employing the IEFPCM solvation model for either $\mathrm{CH}_{2} \mathrm{Cl}_{2}$ or water, and $\mathrm{B} 97 \mathrm{D} / 6-311+\mathrm{G}(\mathrm{d}, \mathrm{p})$ employing the CPCM solvation model for either $\mathrm{CH}_{2} \mathrm{Cl}_{2}$ or water. Energies for the preferred regioisomer are in bold typeface.

\begin{tabular}{|c|c|c|c|c|c|c|c|c|c|c|}
\hline \multirow{3}{*}{ Method } & \multirow{3}{*}{ Solvent } & \multirow{3}{*}{ Compound } & \multicolumn{4}{|c|}{ syn TS } & \multicolumn{4}{|c|}{ anti TS } \\
\hline & & & \multicolumn{3}{|c|}{$\Delta E^{\ddagger}{ }_{\text {distortion }}$} & \multirow{2}{*}{$\Delta E^{\ddagger}{ }_{\text {interaction }}$} & \multicolumn{3}{|c|}{$\Delta E^{\ddagger_{\text {distortion }}}$} & \multirow{2}{*}{$\Delta E^{\ddagger}$ interaction } \\
\hline & & & 1,3-Dipole & Alkyne & Total & & 1,3-Dipole & Alkyne & Total & \\
\hline \multirow{7}{*}{ M06-2X } & $\mathrm{CH}_{2} \mathrm{Cl}_{2}$ & DIBO & 18.6 & 5.0 & 23.7 & -13.0 & - & - & - & - \\
\hline & & DIBAC & 17.5 & 4.3 & 21.8 & -11.7 & 17.5 & 4.4 & 21.9 & -13.1 \\
\hline & & $2-A B C$ & 16.8 & 3.8 & 20.6 & -15.1 & 18.5 & 5.2 & 23.6 & -12.9 \\
\hline & & $3-A B C$ & 18.0 & 4.8 & 22.8 & -12.9 & 18.1 & 5.0 & 23.1 & -13.3 \\
\hline & & $4-A B C$ & 17.9 & 5.0 & 22.9 & -13.0 & 18.2 & 5.0 & 23.1 & -13.4 \\
\hline & & $5-A B C$ & 18.2 & 4.9 & 23.1 & -12.6 & 18.3 & 4.9 & 23.2 & -13.4 \\
\hline & & $6-A B C$ & 17.4 & 5.6 & 23.0 & -15.9 & 16.6 & 5.7 & 22.3 & -16.2 \\
\hline \multirow[t]{7}{*}{ M06-2X } & $\mathrm{H}_{2} \mathrm{O}$ & DIBO & 18.6 & 5.0 & 23.6 & -13.0 & - & - & - & - \\
\hline & & DIBAC & 17.6 & 4.2 & 21.9 & -11.7 & 17.1 & 4.4 & 21.5 & -12.6 \\
\hline & & $2-A B C$ & 16.8 & 3.7 & 20.5 & -14.3 & 18.3 & 5.1 & 23.4 & -12.8 \\
\hline & & $3-A B C$ & 18.1 & 4.8 & 22.9 & -12.9 & 18.0 & 5.0 & 23.0 & -13.2 \\
\hline & & $4-A B C$ & 18.0 & 5.0 & 23.0 & -13.1 & 18.2 & 4.9 & 23.1 & -13.3 \\
\hline & & $5-A B C$ & 18.3 & 4.9 & 23.2 & -12.9 & 18.1 & 48 & 23.0 & -12.9 \\
\hline & & $6-A B C$ & 17.2 & 5.4 & 22.6 & -15.5 & 16.7 & 5.6 & 22.3 & -15.5 \\
\hline \multirow[t]{7}{*}{ B97D } & $\mathrm{CH}_{2} \mathrm{Cl}_{2}$ & DIBO & 17.1 & 4.5 & 21.6 & -13.8 & - & - & - & - \\
\hline & & DIBAC & 15.8 & 3.7 & 19.5 & -12.6 & 15.4 & 3.9 & 19.3 & -13.3 \\
\hline & & $2-A B C$ & 16.0 & 3.5 & 19.5 & -16.0 & 16.9 & 4.6 & 21.5 & -13.2 \\
\hline & & $3-A B C$ & 16.4 & 4.3 & 20.7 & -13.7 & 16.4 & 4.4 & 20.8 & -13.8 \\
\hline & & 4-ABC & 16.4 & 4.4 & 20.8 & -13.7 & 16.6 & 4.3 & 21.0 & -13.9 \\
\hline & & $5-A B C$ & 16.7 & 4.5 & 21.2 & -13.5 & 16.8 & 4.3 & 21.1 & -13.9 \\
\hline & & $6-A B C$ & 15.7 & 5.1 & 20.8 & -16.2 & 15.0 & 5.4 & 20.4 & -16.4 \\
\hline \multirow[t]{7}{*}{ B97D } & $\mathrm{H}_{2} \mathrm{O}$ & DIBO & 17.0 & 4.4 & 21.5 & -13.5 & - & - & - & - \\
\hline & & DIBAC & 15.8 & 3.6 & 19.4 & -12.3 & 15.4 & 3.9 & 19.3 & -13.1 \\
\hline & & $2-A B C$ & 16.0 & 3.5 & 19.5 & -15.4 & 16.8 & 4.6 & 21.4 & -13.1 \\
\hline & & $3-A B C$ & 16.3 & 4.3 & 20.6 & -13.2 & 16.3 & 4.4 & 20.7 & -13.6 \\
\hline & & $4-A B C$ & 16.3 & 4.4 & 20.7 & -13.5 & 16.5 & 4.3 & 20.8 & -13.6 \\
\hline & & $5-A B C$ & 16.6 & 4.5 & 21.1 & -13.4 & 16.7 & 4.2 & 20.9 & -13.5 \\
\hline & & $6-A B C$ & 15.6 & 5.1 & 20.7 & -15.9 & 15.0 & 5.4 & 20.4 & -15.8 \\
\hline
\end{tabular}


Table S4. Energies and free energies of activation $(\mathrm{kcal} / \mathrm{mol})$ for cycloadditions of $N$-substituted 2-diazoacetamides and $N$-substituted 2-azidoacetamides $(\mathrm{R}=\mathrm{H}$ or $\mathrm{Me})$ with $\mathrm{ABC}$. Geometries optimized at both M06-2X/6-311++G(d,p) employing the IEFPCM solvation model for either $\mathrm{CH}_{2} \mathrm{Cl}_{2}$ or water, and $\mathrm{B} 97 \mathrm{D} / 6-311+\mathrm{G}(\mathrm{d}, \mathrm{p})$ employing the CPCM solvation model for either $\mathrm{CH}_{2} \mathrm{Cl}_{2}$ or water. Energies for the preferred regioisomer are in bold typeface.

\begin{tabular}{|c|c|c|c|c|c|c|c|c|c|c|}
\hline \multirow{3}{*}{ Method } & \multirow{3}{*}{ Solvent } & \multirow{3}{*}{$\mathbf{R}$} & \multicolumn{4}{|c|}{ 2-azido-N-R-N-methylacetamide } & \multicolumn{4}{|c|}{ 2-diazo-N-R-N-methylacetamide } \\
\hline & & & \multicolumn{2}{|c|}{ syn TS } & \multicolumn{2}{|c|}{ anti TS } & \multicolumn{2}{|c|}{ syn TS } & \multicolumn{2}{|c|}{ anti TS } \\
\hline & & & $\Delta E^{\ddagger}$ & $\Delta G^{\ddagger}$ & $\Delta E^{\ddagger}$ & $\Delta G^{\ddagger}$ & $\Delta E^{\ddagger}$ & $\Delta G^{\ddagger}$ & $\Delta E^{\ddagger}$ & $\Delta G^{\ddagger}$ \\
\hline \multirow[t]{4}{*}{ M06-2X } & $\mathrm{CH}_{2} \mathrm{Cl}_{2}$ & $\mathrm{H}$ & 7.3 & 20.6 & 10.1 & 23.1 & 5.0 & 18.4 & 10.3 & 23.2 \\
\hline & $\mathrm{H}_{2} \mathrm{O}$ & $\mathrm{H}$ & 7.9 & 21.5 & 10.2 & 23.3 & 5.7 & 19.1 & 10.2 & 23.2 \\
\hline & $\mathrm{CH}_{2} \mathrm{Cl}_{2}$ & $\mathrm{Me}$ & 8.1 & 20.5 & 9.8 & 24.3 & 7.1 & 20.8 & 10.9 & 24.9 \\
\hline & $\mathrm{H}_{2} \mathrm{O}$ & $\mathrm{Me}$ & 8.6 & 21.3 & 9.8 & 24.3 & 7.5 & 21.1 & 10.9 & 25.0 \\
\hline \multirow[t]{4}{*}{ B97D } & $\mathrm{CH}_{2} \mathrm{Cl}_{2}$ & $\mathrm{H}$ & 3.6 & 18.1 & 6.1 & 20.5 & 3.2 & 16.9 & 8.0 & 21.1 \\
\hline & $\mathrm{H}_{2} \mathrm{O}$ & $\mathrm{H}$ & 4.0 & 17.3 & 6.3 & 19.6 & 3.7 & 17.3 & 8.1 & 21.2 \\
\hline & $\mathrm{CH}_{2} \mathrm{Cl}_{2}$ & $\mathrm{Me}$ & 5.1 & 18.6 & 6.3 & 21.0 & 5.1 & 18.3 & 7.9 & 21.4 \\
\hline & $\mathrm{H}_{2} \mathrm{O}$ & $\mathrm{Me}$ & 5.8 & 18.5 & 6.8 & 21.2 & 5.4 & 18.8 & 8.0 & 21.6 \\
\hline
\end{tabular}


A

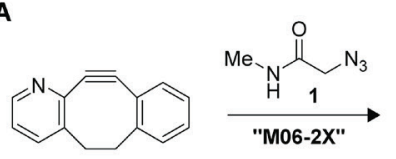

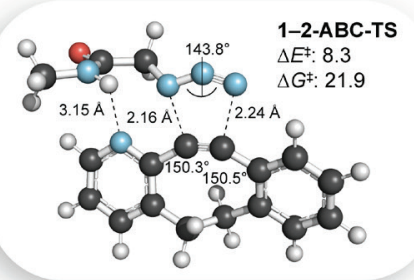

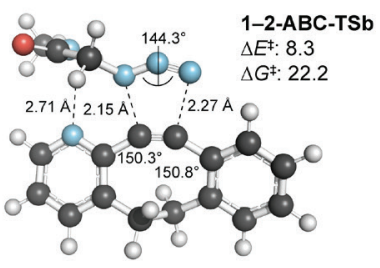

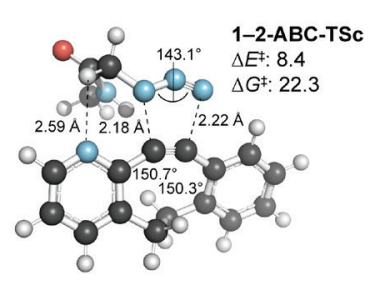
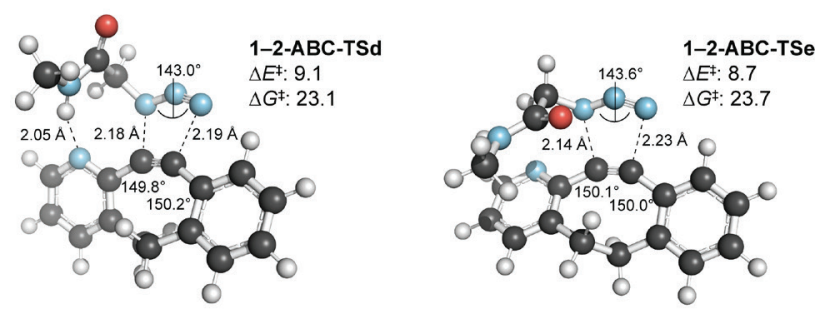

B
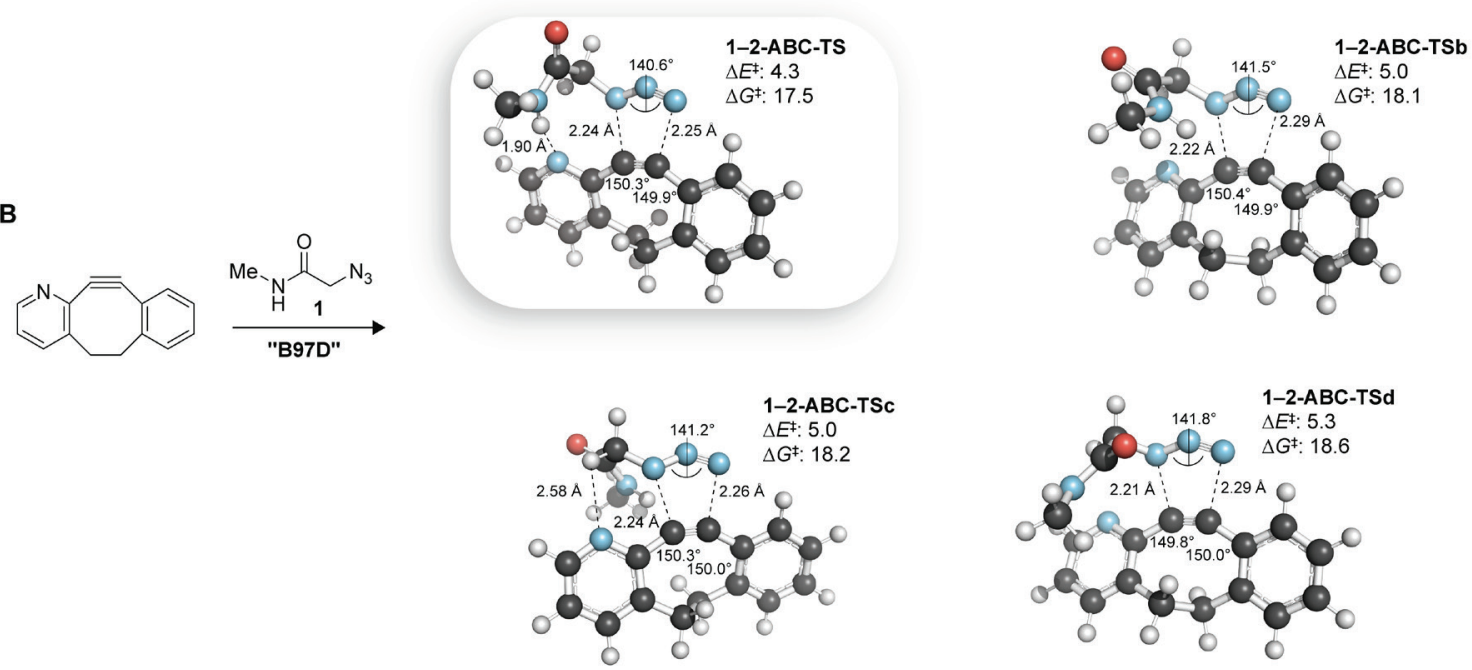

Figure S1. Optimized transition state geometries for the syn reaction of 2-azido$N$-methylacetamide (1) with 2-ABC at (A) the M06-2X/6-311++G(d,p) employing the IEFPCM solvation model for water, and (B) the B97D/6-311+G(d,p) employing the CPCM solvation model for water. 
A<smiles>CNC(=O)C(C)N</smiles>
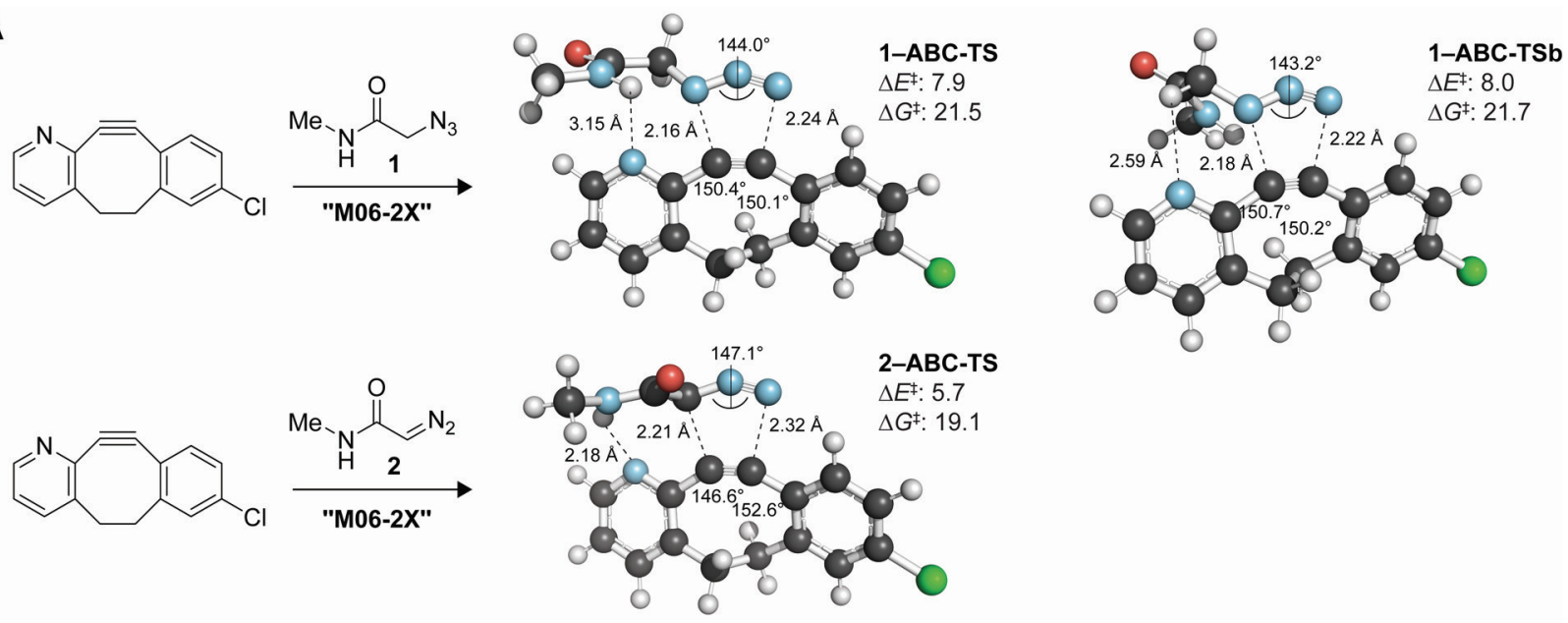

B
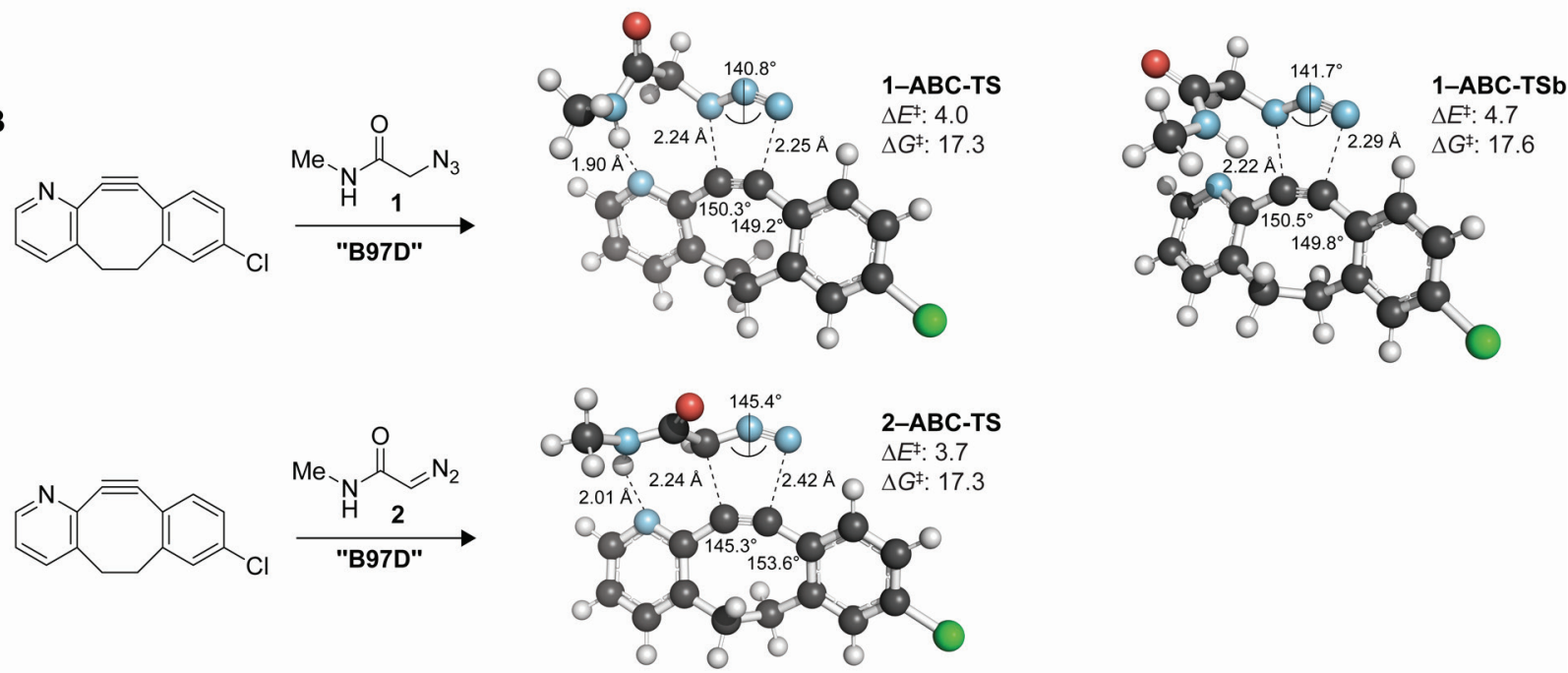

Figure S2. Optimized transition state geometries for the reaction of 2-azido- $N$-methylacetamide (1) and 2-diazo- $N$-methylacetamide (2) with $\mathrm{ABC}$ at the M06-2X/6-311++G(d,p) employing the IEFPCM solvation model for water (A), and the B97D/6-311+G(d,p) employing the CPCM solvation model for water (B). 


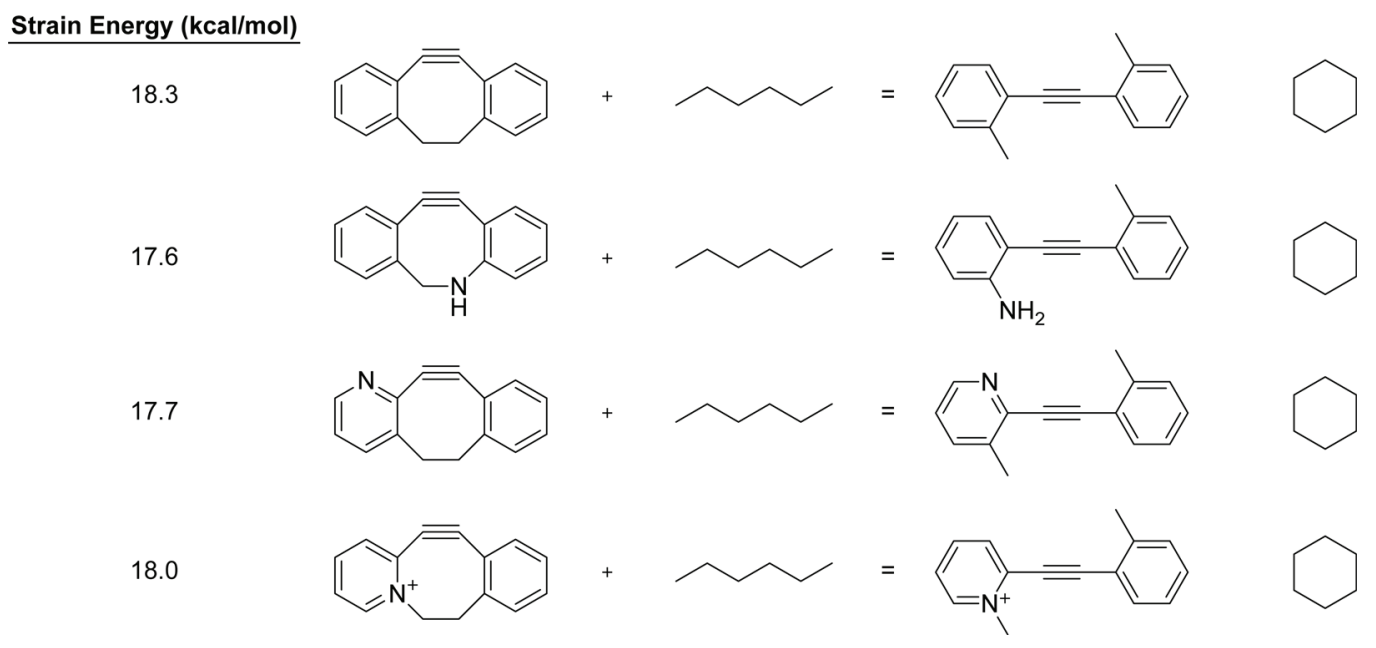

Figure S3. Isodesmic equations used to calculate strain energies of dibenzocyclooctyne (DIBO), dibenzoazacyclooctyne (DIBAC), 2-azabenzo-benzocyclooctyne (2-ABC), and 6-azabenzobenzocyclooctyne (6-ABC) calculated at the M06-2X/6-311++G(d,p) employing the IEFPCM solvation model (water). A correction of $2.2 \mathrm{kcal} / \mathrm{mol}$ was used to account for the nonzero strain energy of cyclohexane. ${ }^{\text {S9 }}$
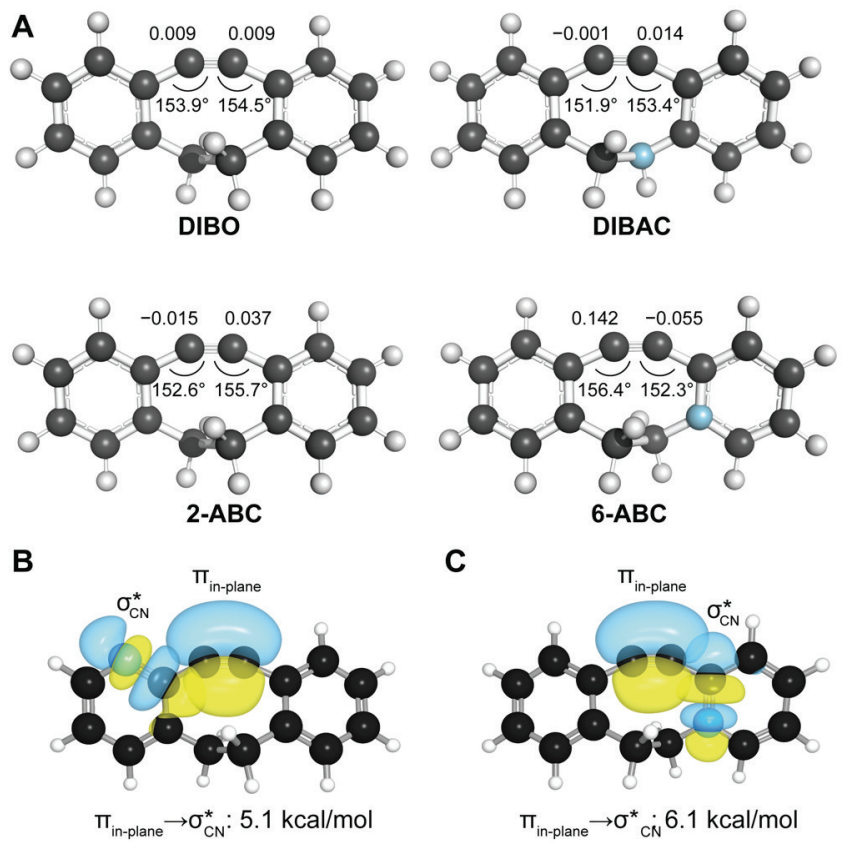

Figure S4. Combining increased strain with electronic activation. (A) Optimized geometries and NBO charge on each alkyne carbon of dibenzocyclooctyne (DIBO), dibenzoazacyclooctyne (DIBAC), 2-azabenzo-benzocyclooctyne (2-ABC), and 6-azabenzo-benzocyclooctyne (6-ABC) calculated at the B97D/6-311+G(d,p) employing the CPCM solvation model (water). (B,C) Natural bonding orbitals depicting $\pi_{\mathrm{CC}} \rightarrow \sigma^{*}{ }_{\mathrm{CN}}$ interactions with the the syn-periplanar $\mathrm{C}-\mathrm{N}$ bond in 2-ABC (B) and anti-periplanar $\mathrm{C}-\mathrm{N}$ bond in 6- $\mathrm{ABC}(\mathrm{C})$. 
A
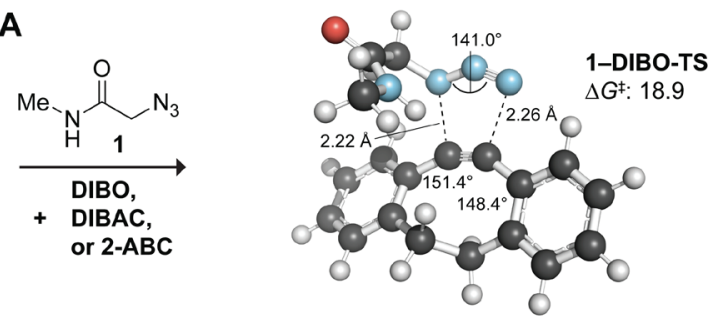

B
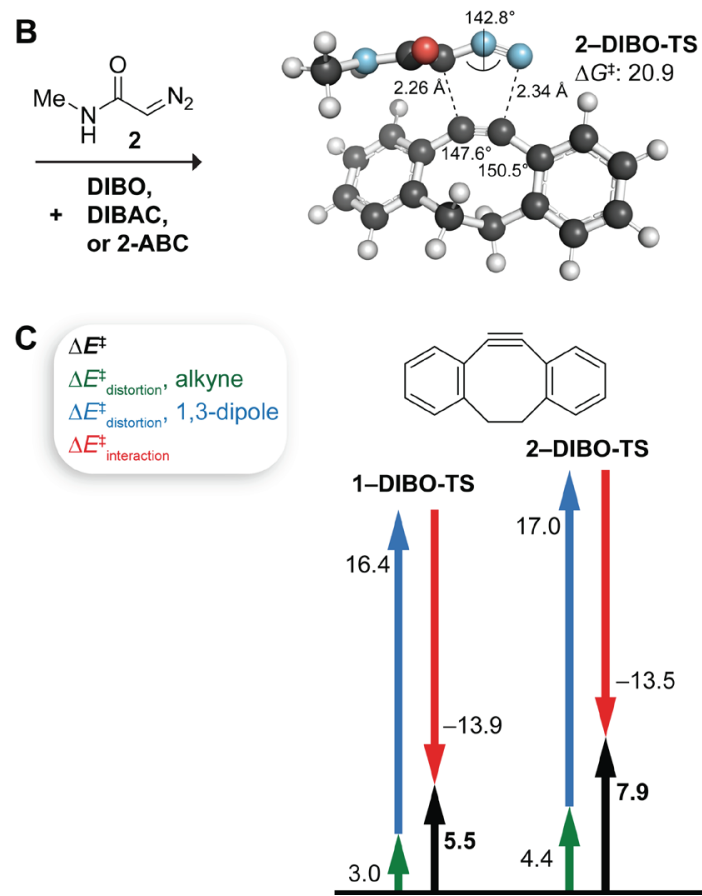
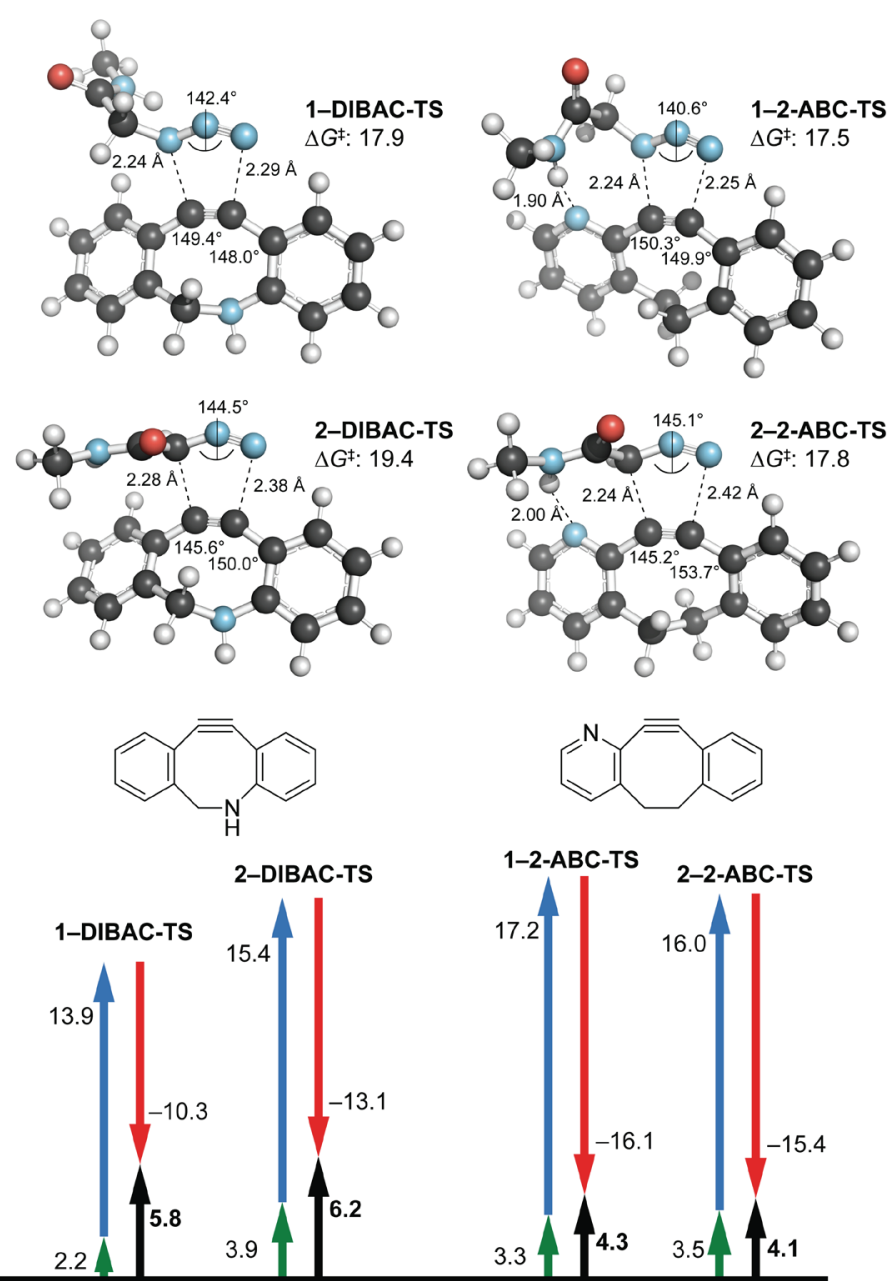

Figure S5. Computational analysis of cycloadditions with 2 -azido- $N$-methylacetamide (1) and 2diazo- $N$-methylacetamide (2). (A,B) Optimized transition state geometries and free energies of activation ( $\mathrm{kcal} / \mathrm{mol})$ calculated at the B97D/6-311+G(d,p) level employing the CPCM solvation model (water). (C) Distortion/Interaction (Strain-Activation) analysis.

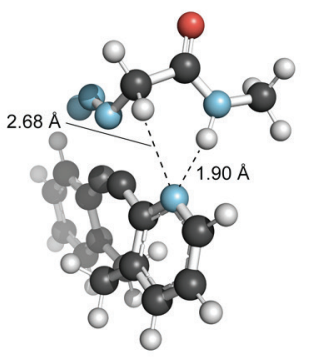

1-2-ABC-TS $\Delta G^{\ddagger}: 17.5$

$\mathrm{n}_{\mathrm{N}} \rightarrow \sigma_{\mathrm{NH}}^{*}: 14.0 \mathrm{kcal} / \mathrm{mol}$

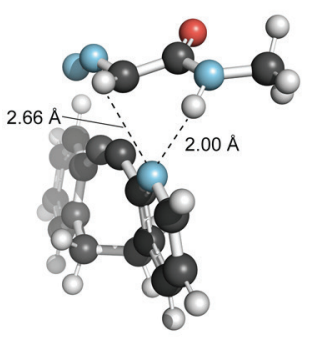

2-2-ABC-TS

$\triangle G^{\ddagger}: 17.8$

$\mathrm{n}_{\mathrm{N}} \rightarrow \sigma_{\mathrm{NH}}^{*}: 7.4 \mathrm{kcal} / \mathrm{mol}$

Figure S6. Comparison of hydrogen bonding interactions in 2-ABC cycloadditions with 2-azido$N$-methylacetamide (1) (left) and 2-diazo- $N$-methylacetamide (2) (right). Second-order perturbations obtained from the NBO analysis provide a measure of relative hydrogen bond strengths. Optimized transition state geometries are from Figure S5. 

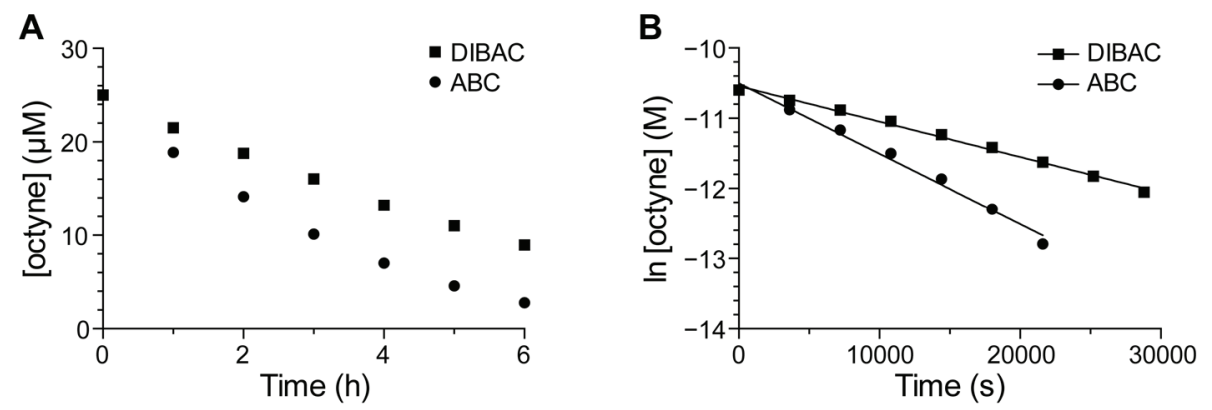

Figure S8. Stability of DIBAC and ABC in the presence of $1 \mathrm{mM}$ reduced glutathione and $0.2 \mathrm{mM}$ oxidized glutathione in PBS containing DMSO $(2 \% \mathrm{v} / \mathrm{v})$ at $37^{\circ} \mathrm{C}$. (A) Concentration of remaining DIBAC and ABC as determined by HPLC. (B) Natural logarithm of the concentration of DIBAC and $\mathrm{ABC}$ over time in order to determine the first-order half-life of each cyclooctyne. The halflives were $3.8 \mathrm{~h}$ and $1.9 \mathrm{~h}$ for DIBAC and $\mathrm{ABC}$, respectively. Values are the mean $\pm \mathrm{SD}$ for triplicate experiments. (Error bars are smaller than the data points.) 


\section{Experimental Procedures}

General. All chemicals were from commercial sources and were used without further purification. NMR spectra were acquired with an Avance Neo 400 spectrometer or Avance Neo 500 spectrometer from Bruker (Billerica, MA, USA). Mass spectra were acquired by using positive ionization with an AccuTOF-DART 4G instrument from JEOL (Tokyo, Japan). HPLC experiments were carried out on a 1200 series HPLC from Agilent Technologies (Santa Clara, CA, USA) equipped with a Varian Microsorb-MV 100-5 C18 $250 \times 4.6 \mathrm{~mm}$ column. Gradients were run with water containing TFA $(0.1 \% \mathrm{v} / \mathrm{v})$ and ACN containing TFA $(0.1 \% \mathrm{v} / \mathrm{v})$. Absorbance was measured at $280 \mathrm{~nm}$. Column chromatography was performed with an Isolera automated purification system from Biotage (Uppsala, Sweden) using prepacked SNAP KP silica gel columns. Thermostability was assessed with a Stanford Research Systems Optimelt automated melting point system.

The phrase "concentrated under reduced pressure" refers to the removal of solvents and other volatile materials using a rotary evaporator at water aspirator pressure $(<20$ Torr $)$ while maintaining the water-bath temperature of $40^{\circ} \mathrm{C}$. Residual solvent was removed from samples by the vacuum $(<0.1$ Torr $)$ achieved by a mechanical belt-drive oil pump.

All procedures were performed in air at ambient temperature $\left(\sim 22^{\circ} \mathrm{C}\right)$ and pressure $(1.0 \mathrm{~atm})$ unless indicated otherwise.

2-Azido-N-benzylacetamide (5) and 2-diazo-N-benzylacetamide (6). These compounds were synthesized as reported previously. ${ }^{\mathrm{S} 10}$

4-((N-Tetrazolyl)methyl)morpholine (8). To a cold $\left(0{ }^{\circ} \mathrm{C}\right)$, stirred solution of tetrazole $(0.70 \mathrm{~g}, 10.0 \mathrm{mmol}, 1.0$ equiv) in methanol $(10 \mathrm{~mL})$ was added morpholine $(0.957 \mathrm{~g}, 0.95 \mathrm{~mL}$, $11.0 \mathrm{mmol}, 1.1$ equiv), and the mixture was stirred for $15 \mathrm{~min}$. An aqueous solution of $37 \% \mathrm{v} / \mathrm{v}$ formaldehyde $(0.98 \mathrm{~mL}, 12.0 \mathrm{mmol}, 1.2$ equiv) was added dropwise, and the mixture was stirred overnight at room temperature. The reaction mixture was then concentrated under reduced pressure, and the residue was recrystallized from a 1:2 v/v mixture of $\mathrm{CH}_{2} \mathrm{Cl}_{2}$ and hexanes to provide compound 8 as a mixture of $N$ tautomers, as white crystals $(1.48 \mathrm{~g}, 8.74 \mathrm{mmol}, 88 \%)$. All spectral data matches published data. ${ }^{11}{ }^{1} \mathbf{H}$ NMR $\left(400 \mathrm{MHz}, \mathrm{CDCl}_{3}, \delta\right): 8.67(\mathrm{~s}, 0.2 \mathrm{H}), 8.56(\mathrm{~s}$, $0.8 \mathrm{H}), 5.53(\mathrm{~s}, 1.6 \mathrm{H}), 5.31(\mathrm{~s}, 0.4 \mathrm{H}), 3.82-3.61(\mathrm{~m}, 4 \mathrm{H}), 2.69-2.65(\mathrm{~m}, 3.2 \mathrm{H}), 2.62(\mathrm{t}, J=4.7 \mathrm{~Hz}$, 0.8H). ${ }^{13} \mathbf{C ~ N M R ~ ( 1 0 1 ~ M H z , ~} \mathrm{CDCl}_{3}, \delta$ ): 152.69, 74.00, 66.64, 66.44, 49.85, 49.76. HRMS m/z calcd for $\mathrm{C}_{6} \mathrm{H}_{12} \mathrm{~N}_{5} \mathrm{O}[\mathrm{M}+\mathrm{H}]^{+}, 170.10364$; found, 170.10408 .

8-Chloro-11-(1H-tetrazol-5-yl)-6,11-dihydro-5H-benzo[5,6]cyclohepta[1,2-b]pyridin-11ol (4). To a stirred solution of 4-((N-tetrazolyl)methyl)morpholine (8) $(0.70 \mathrm{~g}, 4.12 \mathrm{mmol}$, 2.0 equiv) and 8 -chloro-5H-benzo[5,6]cyclohepta[1,2-b]pyridin-11(6H)-one (3) (0.50 g, $2.06 \mathrm{mmol}, 1.0$ equiv) in THF $(10 \mathrm{~mL})$, under $\mathrm{N}_{2}(\mathrm{~g})$ at $-78{ }^{\circ} \mathrm{C}$ (acetone/ $\left.\mathrm{CO}_{2}\right)$, was added $1 \mathrm{M}$ LiHMDS in THF (4.33 mL, $4.33 \mathrm{mmol}, 2.1$ equiv) dropwise via a syringe. The reaction mixture was stirred for $2 \mathrm{~h}$ at $-78{ }^{\circ} \mathrm{C}$ then allowed to warm to room temperature overnight. The reaction mixture was concentrated under reduced pressure, and the remaining residue was treated with aqueous $\mathrm{HCl}(1 \mathrm{M}, 25 \mathrm{~mL})$ and stirred at room temperature for $1 \mathrm{~h}$. The solution was then extracted with EtOAc $(3 \times 50 \mathrm{~mL})$, and the combined organic extracts were dried over $\mathrm{Na}_{2} \mathrm{SO}_{4}(\mathrm{~s})$, filtered, and concentrated under reduced pressure. The residue was purified by flash column chromatography on silica gel (hexanes/EtOAc $85: 15 \rightarrow 25: 75)$ to provide compound $4(0.336 \mathrm{~g}$, $1.07 \mathrm{mmol}, 52 \%)$ as a white solid. ${ }^{1} \mathbf{H}$ NMR $\left(500 \mathrm{MHz}, \mathrm{CDCl}_{3}, \delta\right): 8.78(\mathrm{~s}, 1 \mathrm{H}), 8.46(\mathrm{~s}, 1 \mathrm{H}), 8.09$ $(\mathrm{dd}, J=8.4,4.0 \mathrm{~Hz}, 1 \mathrm{H}), 7.64(\mathrm{~d}, J=7.6 \mathrm{~Hz}, 1 \mathrm{H}), 7.37(\mathrm{~d}, J=6.6 \mathrm{~Hz}, 1 \mathrm{H}), 7.25$ (d, $J=8.9 \mathrm{~Hz}$, $1 \mathrm{H}), 7.17(\mathrm{~s}, 1 \mathrm{H}), 3.40-3.32(\mathrm{~m}, 1 \mathrm{H}), 3.05-2.93(\mathrm{~m}, 3 \mathrm{H}), 2.74-2.67(\mathrm{~m}, 1 \mathrm{H}) .{ }^{13} \mathbf{C ~ N M R}(126 \mathrm{MHz}$, $\left.\mathrm{CDCl}_{3}, \delta\right): 161.98,152.43,143.57,142.67,141.72,140.09,138.54,134.70,134.38,129.45$, 
127.21, 126.36, 124.64, 30.81, 29.95. HRMS $m / z$ calcd for $\mathrm{C}_{15} \mathrm{H}_{13} \mathrm{ON}_{5} \mathrm{Cl}[\mathrm{M}+\mathrm{H}]^{+}, 314.08086$; found, 314.08960 .

2-Azabenzo-8-chlorobenzocyclooctyne (ABC). To a stirred solution of compound 4 $(0.514 \mathrm{~g}, 1.64 \mathrm{mmol}, 1.0$ equiv) in THF $(5.0 \mathrm{~mL})$, was treated with EDC $(0.345 \mathrm{~g}, 1.80 \mathrm{mmol}$, 1.1 equiv) and allowed to react overnight. The reaction mixture was concentrated under reduced pressure, and the residue was purified by flash column chromatography on silica gel (hexanes/EtOAc 85:15 $\rightarrow 25: 75)$ to provide ABC (0.157 $\mathrm{g}, 0.66 \mathrm{mmol}, 40 \%)$ as a pale yellow solid. mp: decomposition observed at $\geq 80{ }^{\circ} \mathrm{C}$. ${ }^{1} \mathbf{H} \mathbf{~ N M R}\left(500 \mathrm{MHz}, \mathrm{CDCl}_{3}, \delta\right): 8.44$ (dd, $J=5.0,1.6 \mathrm{~Hz}$, $1 \mathrm{H}), 7.51(\mathrm{dd}, J=7.6,1.6 \mathrm{~Hz}, 1 \mathrm{H}), 7.30-7.20$ (m, 3H), $7.12(\mathrm{dd}, J=7.7,4.9 \mathrm{~Hz}, 1 \mathrm{H}), 3.30-3.18$ $(\mathrm{m}, 2 \mathrm{H}), 2.36$ (ddq, $J=15.1,8.5,3.7 \mathrm{~Hz}, 2 \mathrm{H}) .{ }^{13} \mathbf{C}$ NMR $\left(126 \mathrm{MHz}, \mathrm{CDCl}_{3}, \delta\right): 155.00,148.55$, $147.75,144.65,136.34,134.52,129.74,127.45,126.88,121.97,121.20,113.31,109.88,35.62$, 34.79. HRMS $\mathrm{m} / \mathrm{z}$ calcd for $\mathrm{C}_{15} \mathrm{H}_{11} \mathrm{NCl}[\mathrm{M}+\mathrm{H}]^{+}$, 240.05800; found, 240.06485. The atomnumbering and IUPAC name of $\mathrm{ABC}$ is as follows:

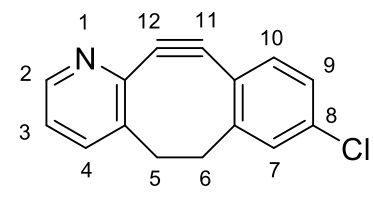

8-chloro-5,6-dihydro-11,12-didehydrobenzo[5,6]cycloocta[1,2-b]pyridine

5-(1H-Tetrazol-5-yl)-10,11-dihydro-5H-dibenzo[a,d][7]annulen-5-ol (9). To a stirred solution of compound $\mathbf{8}(0.413 \mathrm{~g}, 2.44 \mathrm{mmol}, 2.0$ equiv $)$ and dibenzosuberone $(0.25 \mathrm{~g}, 1.22 \mathrm{mmol}$, 1.0 equiv) in THF $(5 \mathrm{~mL})$, under $\mathrm{N}_{2}(\mathrm{~g})$ at $-78{ }^{\circ} \mathrm{C}$ (acetone $\left./ \mathrm{CO}_{2}\right)$, was added $1 \mathrm{M} \mathrm{LiHMDS}$ in THF ( $2.56 \mathrm{mmol}, 2.56 \mathrm{~mL}, 2.1$ equiv) dropwise via a syringe. The reaction mixture was stirred for $2 \mathrm{~h}$ at $-78{ }^{\circ} \mathrm{C}$ then allowed to warm to room temperature overnight. The reaction mixture was concentrated under reduced pressure, and the remaining residue was treated with aqueous $\mathrm{HCl}$ $(1 \mathrm{M}, 25 \mathrm{~mL})$ and stirred at room temperature for $1 \mathrm{~h}$. The solution was then extracted with EtOAc $(3 \times 50 \mathrm{~mL})$, and the combined organic extracts were dried over $\mathrm{Na}_{2} \mathrm{SO}_{4}(\mathrm{~s})$, filtered, and concentrated under reduced pressure. The residue was purified by flash column chromatography on silica gel $\left(2 \% \mathrm{v} / \mathrm{v} \mathrm{MeOH}\right.$ in $\left.\mathrm{CH}_{2} \mathrm{Cl}_{2}\right)$ to provide compound $9(0.3596 \mathrm{~g})$ as a white solid with some impurities but was used in the next step without further purification. ${ }^{1} \mathbf{H}$ NMR (400 $\mathrm{MHz}$, MeOD, $\delta): ~ 8.09-7.99(\mathrm{~m}, 2 \mathrm{H}), 7.31-7.25(\mathrm{~m}, 4 \mathrm{H}), 7.18-7.12(\mathrm{~m}, 2 \mathrm{H}), 2.83(\mathrm{~s}, 4 \mathrm{H}) .{ }^{13} \mathbf{C}$ NMR (101 MHz, MeOD, $\delta$ ): 162.16, 141.12, 137.93, 130.25, 128.05, 125.83, 125.22, 71.82, 32.05. HRMS $m / z$ calcd for $\mathrm{C}_{16} \mathrm{H}_{15} \mathrm{ON}_{4}[\mathrm{M}+\mathrm{H}]^{+}, 279.12458$; found, 279.12665.

Dibenzocyclooctyne (DIBO). A stirred solution of compound 9 (0.200 g, $0.72 \mathrm{mmol}, 1.0$ equiv) in $\mathrm{CH}_{2} \mathrm{Cl}_{2}(4 \mathrm{~mL})$ was treated with $\mathrm{DIC}(0.109 \mathrm{~g}, 0.86 \mathrm{mmol}, 1.2$ equiv) and allowed to react overnight. The reaction mixture was concentrated under reduced pressure and purified by flash column chromatography on silica gel (hexanes) to provide DIBO (0.072 g, $0.373 \mathrm{mmol}, 51 \%)$ as a white solid. ${ }^{1} \mathbf{H}$ NMR $\left(500 \mathrm{MHz}, \mathrm{CDCl}_{3}, \delta\right)$ : 7.38-7.31 (m, 4H), 7.31-7.26 (m, 4aH), 3.383.29 (m, 2H), 2.50-2.40 (m, 2H). ${ }^{13} \mathbf{C}$ NMR (126 MHz, $\left.\mathrm{CDCl}_{3}, \delta\right): 153.62,129.41,127.69,126.52$, 126.12, 123.95, 111.55, 36.47. HRMS $m / z$ calcd for $\mathrm{C}_{16} \mathrm{H}_{13}[\mathrm{M}+\mathrm{H}]^{+}$, 205.10172; found, 205.10245.

2-Bromo-N-benzyl-N-methylacetamide (10). To a stirred solution of $\mathrm{N}$-methylbenzylamine (0.606 g, $5 \mathrm{mmol}, 1.0$ equiv) and triethylamine $\left(0.7 \mathrm{~mL}, 5 \mathrm{mmol}, 1.0\right.$ equiv) in anhydrous $\mathrm{CH}_{2} \mathrm{Cl}_{2}$ $(10 \mathrm{~mL})$ was added a solution of bromoacetyl bromide (1.06 g, $5.25 \mathrm{mmol}, 1.05$ equiv) in $\mathrm{CH}_{2} \mathrm{Cl}_{2}$ $(2 \mathrm{~mL})$ dropwise at $0{ }^{\circ} \mathrm{C}$. The resulting mixture was allowed to react for $4 \mathrm{~h}$ at room temperature. The reaction was quenched with saturated $\mathrm{NaHCO}_{3}(10 \mathrm{~mL})$ at $0{ }^{\circ} \mathrm{C}$, extracted with diethyl ether 
$(3 \times 25 \mathrm{~mL})$, washed with brine, dried over $\mathrm{Na}_{2} \mathrm{SO}_{4}(\mathrm{~s})$, filtered and concentrated under reduced pressure. The resultant crude material was used in subsequent steps without further purification.

2-Azido- $\mathbf{N}$-benzyl- $\mathbf{N}$-methylacetamide (11). To a stirred solution of compound $\mathbf{1 0}$ (1.34 g, $5.53 \mathrm{mmol}, 1$ equiv) in DMF (25 mL), was added sodium azide (0.719 g, $11.06 \mathrm{mmol}, 2.0$ equiv) and the resulting mixture was allowed to react overnight at room temperature. A mixture of $\mathrm{H}_{2} \mathrm{O} / \mathrm{Et}_{2} \mathrm{O} 1: 1$ was added to the reaction mixture, and the aqueous phase was extracted with $\mathrm{Et}_{2} \mathrm{O}$ $(3 \times 25 \mathrm{~mL})$, the organic extract was then washed with water $(8 \times 20 \mathrm{~mL})$ and brine, and dried over $\mathrm{Na}_{2} \mathrm{SO}_{4}(\mathrm{~s})$. The resulting mixture was concentrated under reduced pressure, and the residue was purified by flash column chromatography on silica gel (hexanes/EtOAc $85: 15 \rightarrow 25: 75$ ) to provide compound $11(0.351 \mathrm{~g}, 31 \%)$ as a colorless oil. ${ }^{1} \mathbf{H} \mathbf{~ N M R}\left(500 \mathrm{MHz}, \mathrm{CDCl}_{3}, \delta\right)$ : 7.31 (ddd, $J=34.5,19.6,7.7 \mathrm{~Hz}, 5 \mathrm{H}), 7.15(\mathrm{~d}, J=7.5 \mathrm{~Hz}, 1 \mathrm{H}), 4.61(\mathrm{~s}, 1 \mathrm{H}), 4.45(\mathrm{~s}, 1 \mathrm{H}), 3.96(\mathrm{~d}, J=11.2$ $\mathrm{Hz}, 2 \mathrm{H}), 3.01(\mathrm{~s}, 1 \mathrm{H}), 2.86$ (s, 2H). ${ }^{13} \mathrm{C}$ NMR (126 MHz, $\mathrm{CDCl}_{3}, \delta$ ): 167.29, 136.47, 135.57, $129.15,128.73,128.24,128.00,127.70,126.21,52.76,51.25,50.64,50.51,34.38,33.88$. HRMS $m / z$ calcd for $\mathrm{C}_{10} \mathrm{H}_{13} \mathrm{ON}_{4}[\mathrm{M}+\mathrm{H}]^{+}, 205.10894$; found, 205.11737 .

2-Diazo-N-benzyl-N-methylacetamide (12). Compound 11 (0.120 g, $0.586 \mathrm{mmol}, 1.0$ equiv) was dissolved in $\mathrm{H}_{2} \mathrm{O}$ /THF 1:9 (20 mL). To this solution was added 2,5-dioxopyrrolidin-1-yl 3(diphenylphosphanyl)propanoate $(0.219 \mathrm{~g}, 0.615 \mathrm{mmol}, 1.05$ equiv), and the reaction mixture was stirred for $4 \mathrm{~h}$ at room temperature before a saturated aqueous solution of $\mathrm{NaHCO}_{3}(15 \mathrm{~mL})$ was added. The reaction mixture was then stirred vigorously for $3 \mathrm{~h}$. The reaction mixture was diluted with brine and extracted with $\mathrm{CH}_{2} \mathrm{Cl}_{2}(3 \times)$. The combined organic extracts were dried over $\mathrm{Na}_{2} \mathrm{SO}_{4}(\mathrm{~s})$, filtered, and concentrated under reduced pressure, and the residue was purified with silica gel chromatography (hexanes/EtOAc 1:1) to provide compound $12(33.3 \mathrm{mg}, 29 \%)$. ${ }^{1} \mathbf{H}$ NMR (400 MHz, $\left.\mathrm{CDCl}_{3}, \delta\right): 7.40-7.21(\mathrm{~m}, 5 \mathrm{H}), 5.01(\mathrm{~s}, 1 \mathrm{H}), 4.65-4.38(\mathrm{~m}, 2 \mathrm{H}), 2.89(\mathrm{~s}, 3 \mathrm{H}) .{ }^{13} \mathrm{C}$ NMR (101 MHz, $\left.\mathrm{CDCl}_{3}, \delta\right): 166.14,128.78,127.55,46.53,34.33,33.98,25.64,24.97$. HRMS $m / z$ calcd for $\mathrm{C}_{10} \mathrm{H}_{12} \mathrm{ON}_{3}[\mathrm{M}+\mathrm{H}]^{+}, 190.09804$; found, 190.10475 .

Cycloaddition General Procedure A. Azides or diazo compounds were dissolved in anhydrous $\mathrm{CH}_{2} \mathrm{Cl}_{2}(0.5 \mathrm{~mL})$ in a scintillation vial at room temperature with stirring. To this solution was added a solution of cyclooctyne in anhydrous $\mathrm{CH}_{2} \mathrm{Cl}_{2}(0.5 \mathrm{~mL})$, and the reaction mixture was stirred overnight. The reaction mixture was concentrated under reduced pressure, and the residue was purified by flash column chromatography on silica gel (hexanes/EtOAc $85: 15 \rightarrow 25: 75)$ to provide the desired product.

ABC-2-azido-N-benzylacetamide Cycloadduct (13). Following Cycloaddition General Procedure A, a solution of azide $5(7.989 \mathrm{mg}, 0.042 \mathrm{mmol})$ dissolved in anhydrous $\mathrm{CH}_{2} \mathrm{Cl}_{2}$ was treated with $\mathrm{ABC}(10 \mathrm{mg}, 0.042 \mathrm{mmol})$ to provide compound $13 .{ }^{1} \mathbf{H} \mathbf{~ N M R}\left(500 \mathrm{MHz}, \mathrm{CDCl}_{3}, \delta\right)$ : $8.27(\mathrm{dd}, J=4.7,1.6 \mathrm{~Hz}, 1 \mathrm{H}), 7.65(\mathrm{dd}, J=7.9,1.6 \mathrm{~Hz}, 1 \mathrm{H}), 7.53(\mathrm{~d}, J=8.2 \mathrm{~Hz}, 1 \mathrm{H}), 7.49(\mathrm{t}, J=$ $5.9 \mathrm{~Hz}, 1 \mathrm{H}), 7.35-7.18(\mathrm{~m}, 8 \mathrm{H}), 5.26(\mathrm{~s}, 2 \mathrm{H}), 4.47(\mathrm{~d}, J=5.7 \mathrm{~Hz}, 2 \mathrm{H}), 3.22(\mathrm{dd}, J=8.3,5.0 \mathrm{~Hz}$, $2 \mathrm{H}), 3.13(\mathrm{dd}, J=8.3,5.0 \mathrm{~Hz}, 2 \mathrm{H}) .{ }^{13} \mathbf{C} \mathbf{N M R}\left(126 \mathrm{MHz}, \mathrm{CDCl}_{3}, \delta\right): 171.19,165.82,147.31$, $144.97,144.36,140.34,139.83,137.80,136.56,134.59,134.46,132.25,129.71,128.70,128.36$, $127.68,127.56,126.93,123.85,52.64,43.62,34.24,33.31$. HRMS $m / z$ calcd for $\mathrm{C}_{24} \mathrm{H}_{21} \mathrm{ON}_{5} \mathrm{Cl}$ $[\mathrm{M}+\mathrm{H}]^{+}$, 430.14346; found, 430.16281.

ABC-N-diazo-N-benzylacetamide Cycloadduct (14). Following Cycloaddition General Procedure A, a solution of diazo compound $6(7.358 \mathrm{mg}, 0.042 \mathrm{mmol})$ dissolved in anhydrous $\mathrm{CH}_{2} \mathrm{Cl}_{2}$ was treated with $\mathrm{ABC}(10 \mathrm{mg}, 0.042 \mathrm{mmol})$ to provide compound $14 .{ }^{1} \mathbf{H} \mathbf{~ N M R}(500 \mathrm{MHz}$, $\left.\mathrm{CDCl}_{3} \mathrm{CDCl}_{3}, \delta\right): 9.77(\mathrm{~s}, 1 \mathrm{H}), 8.10(\mathrm{dd}, J=4.8,1.7 \mathrm{~Hz}, 1 \mathrm{H}), 7.66(\mathrm{dd}, J=7.8,1.7 \mathrm{~Hz}, 1 \mathrm{H}), 7.37-$ $7.12(\mathrm{~m}, 3 \mathrm{H}), 7.25(\mathrm{~m}, 3 \mathrm{H}), 7.19(\mathrm{~d}, J=2.2 \mathrm{~Hz}, 1 \mathrm{H}), 7.15(\mathrm{~m}, 2 \mathrm{H}), 4.58(\mathrm{~d}, J=5.2 \mathrm{~Hz}, 2 \mathrm{H}), 3.34$ $3.22(\mathrm{~m}, 2 \mathrm{H}), 3.11(\mathrm{~d}, J=7.1 \mathrm{~Hz}, 2 \mathrm{H}) .{ }^{13} \mathbf{C}$ NMR $\left(126 \mathrm{MHz}, \mathrm{CDCl}_{3}, \delta\right): 159.67,146.36,139.54$, 
$138.91,137.34,136.84,134.22,134.01,130.07,128.67,127.81,127.51,126.46,123.01,43.92$, 35.45, 32.34. HRMS $m / z$ calcd for $\mathrm{C}_{24} \mathrm{H}_{20} \mathrm{ON}{ }_{4} \mathrm{Cl}[\mathrm{M}+\mathrm{H}]^{+}, 415.13256$; found, 415.14917 .

ABC-2-azido-N-benzyl-N-methylacetamide Cycloadduct (15). Following Cycloaddition General Procedure A, a solution of compound $11(8.578 \mathrm{mg}, 0.042 \mathrm{mmol})$ dissolved in anhydrous $\mathrm{CH}_{2} \mathrm{Cl}_{2}$ was treated with 2-ABC $(10 \mathrm{mg}, 0.042 \mathrm{mmol})$ to provide compound $\mathbf{1 5}$ as regioisomers. ${ }^{1}$ H NMR $\left(500 \mathrm{MHz}, \mathrm{CDCl}_{3}, \delta\right): 8.45(\mathrm{dd}, J=4.7,1.7 \mathrm{~Hz}, 1 \mathrm{H}), 8.37(\mathrm{dd}, J=4.8,1.6 \mathrm{~Hz}, 0.5 \mathrm{H})$, 7.66 (ddd, $J=7.5,5.6,1.7 \mathrm{~Hz}, 2 \mathrm{H}), 7.55(\mathrm{~d}, J=8.3 \mathrm{~Hz}, 1 \mathrm{H}), 7.53(\mathrm{~d}, J=8.3 \mathrm{~Hz}, 1 \mathrm{H}), 7.41-7.33$ $(\mathrm{m}, 2 \mathrm{H}), 7.25(\mathrm{~m}, 8 \mathrm{H}), 7.13-7.07(\mathrm{~m}, 1 \mathrm{H}), 6.94-6.86(\mathrm{~m}, 2 \mathrm{H}), 5.73(\mathrm{~s}, 3 \mathrm{H}), 4.58(\mathrm{~s}, 1 \mathrm{H}), 4.46(\mathrm{~s}$, 2H), 3.35-3.30 (m, 3H), $3.27(\mathrm{dd}, J=8.1,4.7 \mathrm{~Hz}, 3 \mathrm{H}), 2.96(\mathrm{~s}, 3 \mathrm{H}), 2.87(\mathrm{~s}, 2 \mathrm{H}) .{ }^{13} \mathbf{C}$ NMR $(126$ $\left.\mathrm{MHz}, \mathrm{CDCl}_{3}, \delta\right): 165.51,165.25,147.08,146.98,146.16,146.03,144.96,144.93,140.61,139.37$, $139.32,136.84,136.73,136.29,135.41,134.77,134.62,134.16,134.14,132.42,129.81,129.78$, $129.18,128.88,128.86,128.62,128.04,127.75,127.54,126.68,126.67,126.29,123.37,123.31$, $52.70,51.28,50.32,50.11,34.49,34.02,33.98,33.88$. HRMS $m / z$ calcd for $\mathrm{C}_{25} \mathrm{H}_{23} \mathrm{ON}{ }_{5} \mathrm{Cl}[\mathrm{M}+$ $\mathrm{H}]^{+}, 444.15911$; found, 444.18030.

2-ABC-2-diazo-N-benzyl-N-methylacetamide Cycloadduct (16). Following Cycloaddition General Procedure A, a solution of compound $12(8.136 \mathrm{mg}, 0.042 \mathrm{mmol})$ dissolved in anhydrous $\mathrm{CH}_{2} \mathrm{Cl}_{2}$ was treated with 2-ABC $(10 \mathrm{mg}, 0.042 \mathrm{mmol})$ to provide compound $\mathbf{1 6}$ as regioisomers. ${ }^{1} \mathbf{H}$ NMR $\left(500 \mathrm{MHz}, \mathrm{CDCl}_{3}, \delta\right): 8.43(\mathrm{~d}, J=4.7 \mathrm{~Hz}, 1 \mathrm{H}), 8.34-8.27(\mathrm{~m}, 0.59 \mathrm{H}), 7.51(\mathrm{~d}, J=7.5 \mathrm{~Hz}$, 2H), 7.35-7.20 (m, 12H), 7.16-7.03 (m, 3H), $4.69(\mathrm{~s}, 3 \mathrm{H}), 3.25-3.19(\mathrm{~m}, 2 \mathrm{H}), 3.19-3.09(\mathrm{~m}, 5 \mathrm{H})$, 2.89 (s, 2H), 2.87 (s, 3H). ${ }^{13} \mathbf{C}$ NMR (126 MHz, $\left.\mathrm{CDCl}_{3}, \delta\right): 164.85,164.36,149.68,149.43,146.90$, $143.64,143.39$, 141.45, 139.26, 136.76, 136.51, 134.97, 134.83, 133.86, 131.49, 129.94, 129.81, $128.56,128.49,128.23,128.14,127.59,127.39,127.32,126.76,122.05,121.92,121.07,54.84$, $50.94,36.07,34.66,34.45,33.61,33.53,32.82$. HRMS $m / z$ calcd for $\mathrm{C}_{25} \mathrm{H}_{22} \mathrm{ON}{ }_{4} \mathrm{Cl}[\mathrm{M}+\mathrm{H}]^{+}$, 429.14821; found, 429.16635.

ABC-benzyl 2-diazoacetate Cycloadduct (17). Following Cycloaddition General Procedure A, a solution of compound $7(7.399 \mathrm{mg}, 0.042 \mathrm{mmol})$ dissolved in anhydrous $\mathrm{CH}_{2} \mathrm{Cl}_{2}$ was treated with $\mathrm{ABC}(10 \mathrm{mg}, 0.042 \mathrm{mmol})$ to provide compound 17. ${ }^{1} \mathbf{H} \mathbf{~ N M R}\left(400 \mathrm{MHz}, \mathrm{CDCl}_{3}, \delta\right): 11.31$ $(\mathrm{s}, 1 \mathrm{H}), 8.39(\mathrm{dd}, J=4.7,1.7 \mathrm{~Hz}, 1 \mathrm{H}), 7.57(\mathrm{dd}, J=7.8,1.7 \mathrm{~Hz}, 1 \mathrm{H}), 7.34-7.29(\mathrm{~m}, 4 \mathrm{H}), 7.25-$ 7.09 (m, 5H), 5.29 (s, 2H), 3.15 (s, 4H) ${ }^{13}$ C NMR (101 MHz, $\left.\mathrm{CDCl}_{3}, \delta\right): 147.28,137.92,131.99$, $130.18,128.44,128.22,128.08,126.69,122.64,66.92,34.55,33.14$. HRMS $\mathrm{m} / z$ calcd for $\mathrm{C}_{24} \mathrm{H}_{19} \mathrm{O}_{2} \mathrm{~N}_{3} \mathrm{Cl}[\mathrm{M}+\mathrm{H}]^{+}, 416.11658$; found, 416.11660.

DIBO-2-azido-N-benzylacetamide Cycloadduct (18). Following Cycloaddition General Procedure A, a solution of azide $5(7.989 \mathrm{mg}, 0.042 \mathrm{mmol})$ dissolved in anhydrous $\mathrm{CH}_{2} \mathrm{Cl}_{2}$ was treated with DIBO $(10 \mathrm{mg}, 0.042 \mathrm{mmol})$ to provide compound 18. ${ }^{1} \mathbf{H} \mathbf{~ N M R}\left(500 \mathrm{MHz}, \mathrm{CDCl}_{3}\right.$, $\delta): 7.55-7.48(\mathrm{~m}, 1 \mathrm{H}), 7.41-7.17(\mathrm{~m}, 12 \mathrm{H}), 7.14(\mathrm{dd}, J=7.4,1.2 \mathrm{~Hz}, 1 \mathrm{H}), 5.16(\mathrm{~d}, J=16.4 \mathrm{~Hz}$, $1 \mathrm{H}), 5.03(\mathrm{~d}, J=16.6 \mathrm{~Hz}, 1 \mathrm{H}), 4.53(\mathrm{dd}, J=14.7,6.0 \mathrm{~Hz}, 1 \mathrm{H}), 4.43(\mathrm{dd}, J=14.9,5.4 \mathrm{~Hz}, 1 \mathrm{H})$, 3.35 (td, $J=12.1,10.3,4.5 \mathrm{~Hz}, 1 \mathrm{H}), 3.15-3.03(\mathrm{~m}, 2 \mathrm{H}), 2.92-2.81(\mathrm{~m}, 1 \mathrm{H}) .{ }^{13} \mathbf{C} \mathbf{N M R}(126 \mathrm{MHz}$, $\left.\mathrm{CDCl}_{3}, \delta\right): 165.43,147.01,141.71,137.85,137.27,135.18,131.70,130.92,130.46,130.25$, $129.23,129.01,128.81,128.41,127.77,127.72,126.80,126.13,125.14,51.32,43.75,36.34$, 33.02. HRMS $m / z$ calcd for $\mathrm{C}_{25} \mathrm{H}_{23} \mathrm{~N}_{4} \mathrm{O}[\mathrm{M}+\mathrm{H}]^{+}$, 395.18718; found, 395.19003.

DIBO-2-diazo-N-benzylacetamide Cycloadduct (19). Following Cycloaddition General Procedure A, a solution of diazo compound $6(7.350 \mathrm{mg}, 0.042 \mathrm{mmol})$ dissolved in anhydrous $\mathrm{CH}_{2} \mathrm{Cl}_{2}$ was treated with DIBO $(10 \mathrm{mg}, 0.042 \mathrm{mmol})$ to provide compound 19. ${ }^{1} \mathbf{H}$ NMR (500 $\left.\mathrm{MHz}, \mathrm{CDCl}_{3}, \delta\right): 11.58(\mathrm{~s}, 1 \mathrm{H}), 7.34-7.08(\mathrm{~m}, 13 \mathrm{H}), 6.84(\mathrm{~s}, 1 \mathrm{H}), 4.73-4.57(\mathrm{~m}, 1 \mathrm{H}), 4.50-4.39$ (m, 1H), 3.44-2.87 (m, 4H). ${ }^{13} \mathbf{C}$ NMR (126 MHz, $\left.\mathrm{CDCl}_{3}, \delta\right): 171.21,160.59,140.56,139.01$, 137.82 , 131.05, 130.95, 130.91, 130.88, 129.85, 128.68, 128.64, 128.30, 127.69, 127.45, 126.09, 
126.07, 120.39, 43.26, 36.30, 33.18. HRMS $m / z$ calcd for $\mathrm{C}_{25} \mathrm{H}_{22} \mathrm{ON} \mathrm{N}_{3}[\mathrm{M}+\mathrm{H}]^{+}, 380.17629$; found, 380.185730 .

DIBO-benzyl 2-diazoacetate Cycloadduct (20). Following Cycloaddition General Procedure A, a solution of compound 7 (7.399 $\mathrm{mg}, 0.042 \mathrm{mmol})$ dissolved in anhydrous $\mathrm{CH}_{2} \mathrm{Cl}_{2}$ was treated with DIBO (10 mg, $0.042 \mathrm{mmol})$ to provide compound 20. ${ }^{1} \mathbf{H}$ NMR ${ }^{1} \mathrm{H}$ NMR (400 $\left.\mathrm{MHz}, \mathrm{CDCl}_{3}, \delta\right): 9.22(\mathrm{~s}, 1 \mathrm{H}), 7.56-6.91(\mathrm{~m}, 13 \mathrm{H}), 5.48-5.11(\mathrm{~m}, 2 \mathrm{H}), 3.47-2.78(\mathrm{~m}, 4 \mathrm{H}) .{ }^{13} \mathbf{C}$ NMR $\left(101 \mathrm{MHz}, \mathrm{CDCl}_{3}, \delta\right): 139.88,139.22,134.98,131.52,131.23,129.81,129.16,128.51$, 128.36, 128.25, 126.25, 125.66, 67.06, 36.35, 32.84. HRMS $m / z$ calcd for $\mathrm{C}_{25} \mathrm{H}_{21} \mathrm{~N}_{2} \mathrm{O}_{2}[\mathrm{M}+\mathrm{H}]^{+}$, 381.16030; found, 381.16040 .

\section{Kinetic Analyses}

Kinetics General Method A. Stock solutions at the specified concentrations in the specified solvents were prepared for each dipole and dipolarophile. Aliquots $(0.5 \mathrm{~mL})$ of dipole and dipolarophile were mixed, and reactions were monitored by HPLC with aliquots injected at the timepoints shown in the kinetic traces below. Each reaction was carried out in triplicate. The concentration of remaining dipolarophile was obtained from its corresponding peak in the chromatogram monitored at $280 \mathrm{~nm}$. Second-order rate constants were calculated from the slope of the plot of [dipolarophile] $]^{-1}$ versus time.

Kinetics General Method B. Stock solutions of the specified dipoles and dipolarophiles were prepared in DMSO at $2.5 \mathrm{mM}$. An aliquot $(10 \mu \mathrm{L}$ ) of each stock was added to $1 \mathrm{~mL}$ of PBS (final concentration: $25 \mu \mathrm{M}$ ), and reactions were monitored by HPLC with aliquots injected at the timepoints specified in Figure S3. Each reaction was carried out in triplicate. The concentration of remaining dipolarophile was obtained from its corresponding peak in the chromatogram monitored at $280 \mathrm{~nm}$. Second-order rate constants were calculated from the slope of the plot of [dipolarophile] $^{-1}$ versus time.

Reaction of Compound $\mathbf{5}$ with DIBO in $\mathrm{CH}_{2} \mathrm{Cl}_{2}$. Kinetics General Method A was followed using stock solutions at $2 \mathrm{mM}$ and resulting in final reaction concentrations of $1 \mathrm{mM}$ compound $\mathbf{5}$ and $1 \mathrm{mM}$ DIBO.

Reaction of Compound 6 with DIBO in $\mathrm{CH}_{2} \mathrm{Cl}_{2}$. Kinetics General Method A was followed using stock solutions at $2 \mathrm{mM}$ and resulting in final reaction concentrations of $1 \mathrm{mM}$ compound $\mathbf{6}$ and $1 \mathrm{mM}$ DIBO.

Reaction of Compound $\mathbf{5}$ with $\mathrm{ABC}$ in $\mathrm{CH}_{2} \mathrm{Cl}_{2}$. Kinetics General Method A was followed using stock solutions at $20 \mu \mathrm{M}$ and resulting in final reaction concentrations of $10 \mu \mathrm{M}$ compound $\mathbf{5}$ and $10 \mu \mathrm{M} \mathrm{ABC}$.

Reaction of Compound 6 with $\mathrm{ABC}$ in $\mathrm{CH}_{2} \mathrm{Cl}_{2}$. Kinetics General Method A was followed using stock solutions at $80 \mu \mathrm{M}$ and resulting in final reaction concentrations of $40 \mu \mathrm{M}$ compound 6 and $40 \mu \mathrm{M} \mathrm{ABC}$.

Reaction of Compound $\mathbf{7}$ with $\mathrm{ABC}$ in $\mathbf{C H}_{2} \mathbf{C l}_{2}$. Kinetics General Method A was followed using stock solutions at $400 \mu \mathrm{M}$ and resulting in final reaction concentrations of $200 \mu \mathrm{M}$ compound 7 and $200 \mu \mathrm{M}$ ABC.

Reaction of Compound 11 with $\mathrm{ABC}$ in $\mathrm{CH}_{2} \mathrm{Cl}_{2}$. Kinetics General Method A was followed using stock solutions at $80 \mu \mathrm{M}$ and resulting in final reaction concentrations of $40 \mu \mathrm{M}$ compound 11 and $40 \mu \mathrm{M} \mathrm{ABC}$. 
Reaction of Compound 12 with $\mathrm{ABC}$ in $\mathrm{CH}_{2} \mathbf{C l}_{2}$. Kinetics General Method A was followed using stock solutions at $80 \mu \mathrm{M}$ and resulting in final reaction concentrations of $40 \mu \mathrm{M}$ compound 12 and $40 \mu \mathrm{M}$ ABC.

Reaction of Compound 5 with ABC in MeOH. Kinetics General Method A was followed using stock solutions at $20 \mu \mathrm{M}$ and resulting in final reaction concentrations of $10 \mu \mathrm{M}$ compound $\mathbf{5}$ and $10 \mu \mathrm{M} \mathrm{ABC}$.

Reaction of Compound 6 with $\mathrm{ABC}$ in $\mathrm{MeOH}$. Kinetics General Method A was followed using stock solutions at $80 \mu \mathrm{M}$ and resulting in final reaction concentrations of $40 \mu \mathrm{M}$ compound 6 and $40 \mu \mathrm{M}$ ABC.

Reaction of Compound 11 with ABC in MeOH. Kinetics General Method A was followed using stock solutions at $80 \mu \mathrm{M}$ and resulting in final reaction concentrations of $40 \mu \mathrm{M}$ compound 11 and $40 \mu \mathrm{M} \mathrm{ABC}$.

Reaction of Compound 12 with $\mathrm{ABC}$ in $\mathrm{MeOH}$. Kinetics General Method A was followed using stock solutions at $80 \mu \mathrm{M}$ and resulting in final reaction concentrations of $40 \mu \mathrm{M}$ compound 12 and $40 \mu \mathrm{M}$ ABC.

Reaction of Compound 5 with ABC in PBS Containing DMSO (2\% v/v). Kinetics General Method B was followed.

Reaction of Compound 6 with ABC in PBS Containing DMSO (2\% v/v). Kinetics General Method B was followed.

Reaction of Compound 11 with ABC in PBS Containing DMSO (2\% v/v). Kinetics General Method B was followed.

Reaction of Compound 12 with ABC in PBS Containing DMSO (2\% v/v). Kinetics General Method B was followed.

\section{Cyclooctyne Stability Experiments}

A solution of ABC $(25 \mu \mathrm{M})$ or DIBAC $(25 \mu \mathrm{M})$ was prepared in phosphate-buffered saline containing reduced glutathione $(1.0 \mathrm{mM})$, oxidized glutathione $(0.2 \mathrm{mM})$, and DMSO $(2 \% \mathrm{v} / \mathrm{v})$. The solutions were incubated at $37^{\circ} \mathrm{C}$, and HPLC analyses were performed at hourly intervals to determine the remaining concentration of dipolarophile. Subsequently, plots of $\ln$ (concentration) versus time were prepared to calculate half-lives of each cyclooctyne. (Note: The DMSO cosolvent was used to solubilize the alkynes, but does oxidize reduced glutathione. Hence, the ratio of the half-lives is more meaningful than the individual values.) 


\section{Kinetic Traces}

Kinetic traces for the reactions of $\mathrm{ABC}$ with (A) azide 5, (B) diazo compound 6, (C) diazo compound 7, (D) azide $11\left(k=1.0 \mathrm{M}^{-1} \mathrm{~s}^{-1}\right)$, and (E) diazo compound $12\left(k=0.75 \mathrm{M}^{-1} \mathrm{~s}^{-1}\right)$; and the reactions of DIBO with $(\mathrm{F})$ azide 5, $(\mathrm{G})$ diazo compound $\mathbf{6}$, and $(\mathrm{H})$ diazo compound 7. All reactions were carried out in $\mathrm{CH}_{2} \mathrm{Cl}_{2}$ at $26{ }^{\circ} \mathrm{C}$ and were monitored by HPLC. Values are the mean \pm SD for triplicate experiments.
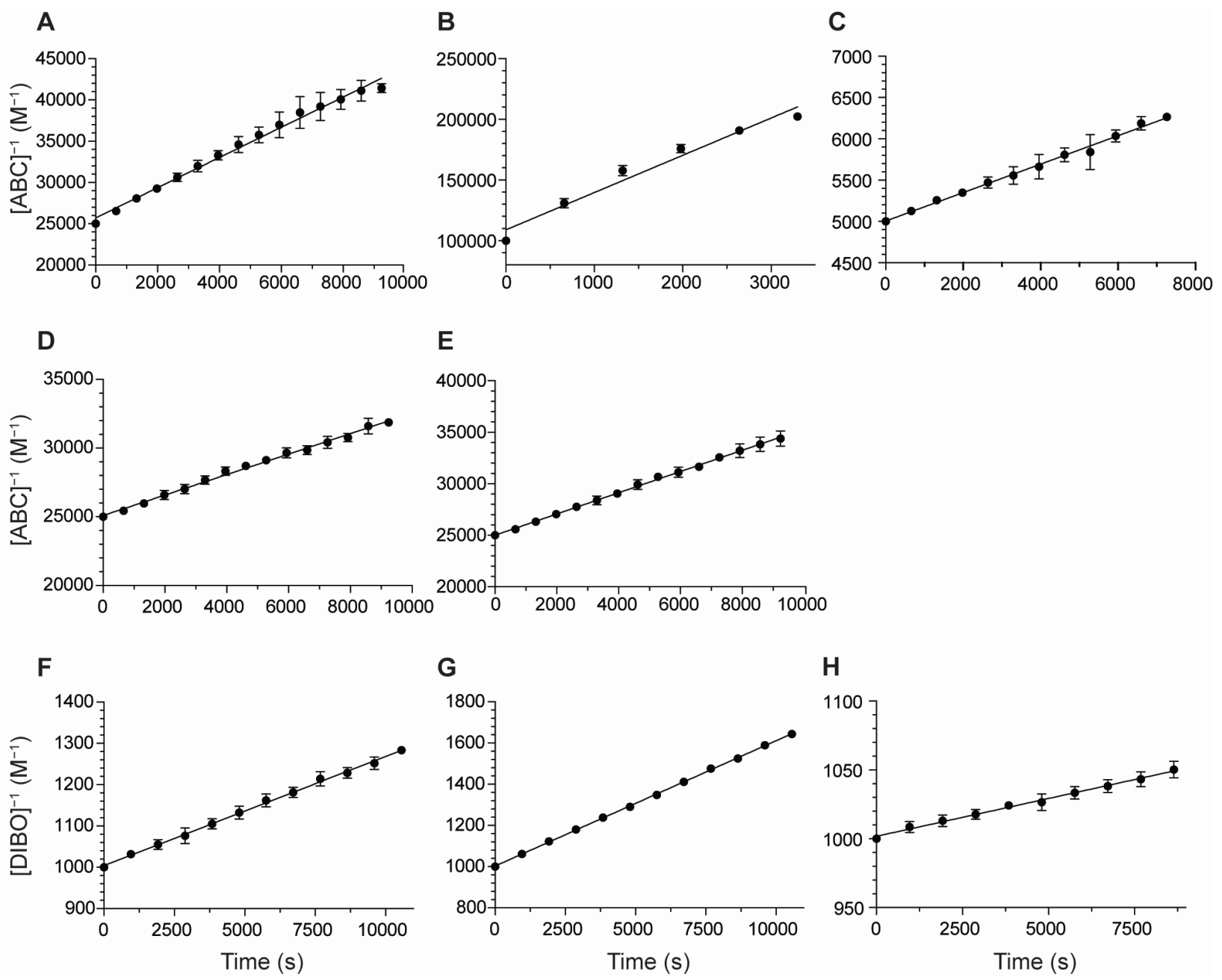
Kinetic traces for the reactions of $\mathrm{ABC}$ with (A) azide 5, (B) diazo compound 6, (C) azide 11, and (D) diazo compound 12. All reactions were carried out in $\mathrm{MeOH}$ at $26^{\circ} \mathrm{C}$ and were monitored by HPLC. Values are the mean \pm SD for triplicate experiments.
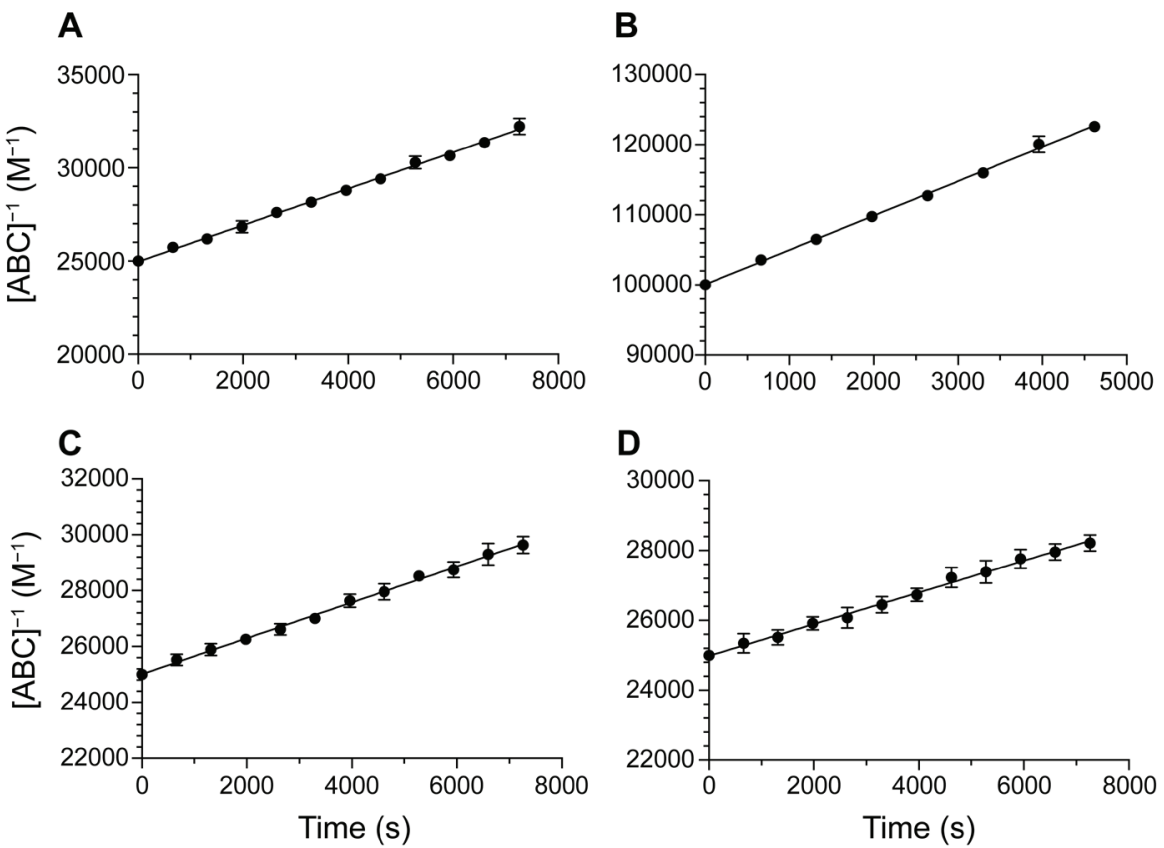

Kinetic traces for the reactions of $\mathrm{ABC}$ with (A) azide 5, (B) diazo compound 6, (C) azide 11, and (D) diazo compound 12. All reactions were carried out in PBS containing DMSO $(2 \% \mathrm{v} / \mathrm{v})$ at $26{ }^{\circ} \mathrm{C}$ and were monitored by HPLC. Values are the mean \pm SD for triplicate experiments.

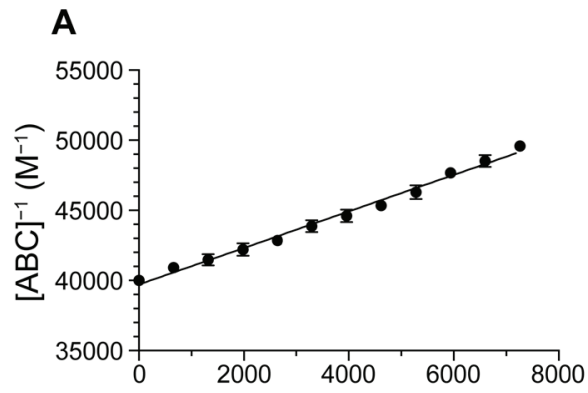

B
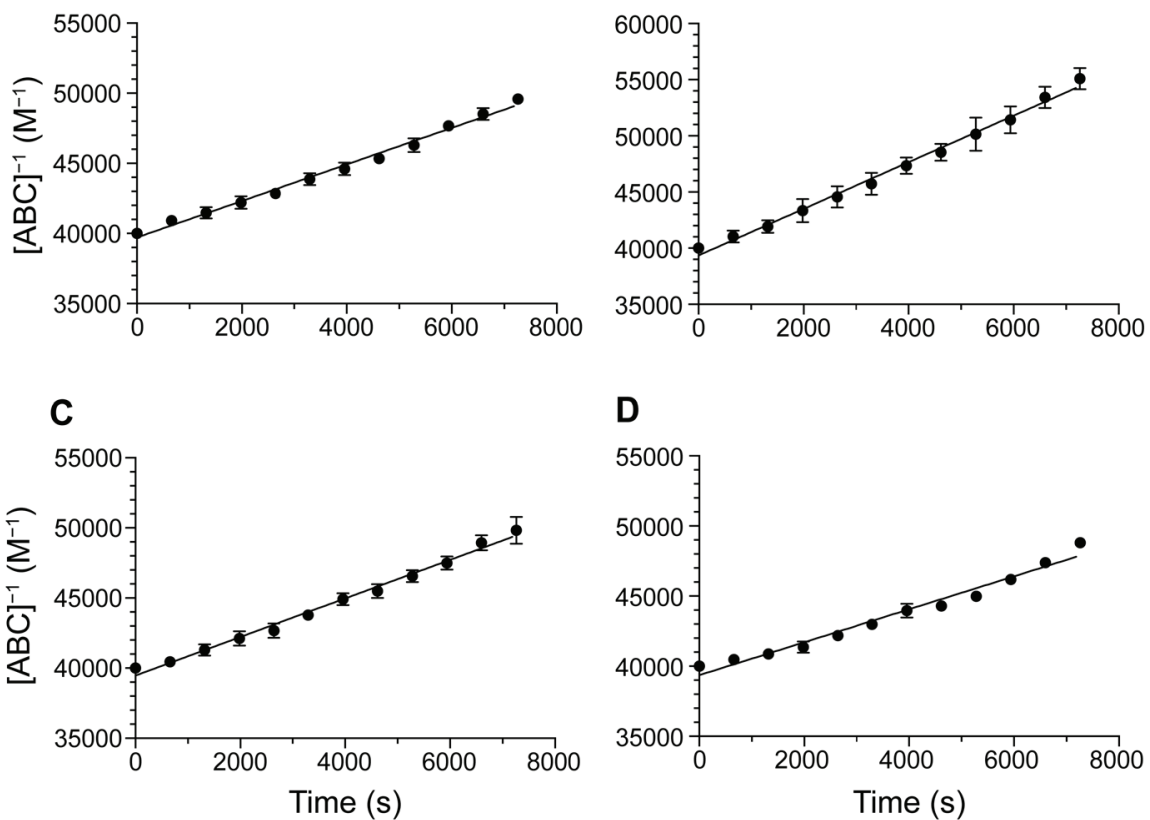

D

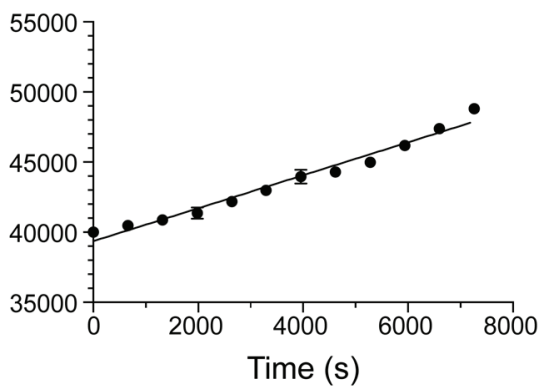




\section{References}

(S1) Frisch, M. J.; Trucks, G. W.; Schlegel, H. B.; Scuseria, G. E.; Robb, M. A.; Cheeseman, J. R.; Scalmani, G.; Barone, V.; Petersson, G. A.; Nakatsuji, H.; Li, X.; Caricato, M.; Marenich, A. V.; Bloino, J.; Janesko, B. G.; Gomperts, R.; Mennucci, B.; Hratchian, H. P.; Ortiz, J. V.; Izmaylov, A. F.; Sonnenberg, J. L.; Williams; Ding, F.; Lipparini, F.; Egidi, F.; Goings, J.; Peng, B.; Petrone, A.; Henderson, T.; Ranasinghe, D.; Zakrzewski, V. G.; Gao, J.; Rega, N.; Zheng, G.; Liang, W.; Hada, M.; Ehara, M.; Toyota, K.; Fukuda, R.; Hasegawa, J.; Ishida, M.; Nakajima, T.; Honda, Y.; Kitao, O.; Nakai, H.; Vreven, T.; Throssell, K.; Montgomery, J. A., Jr.; Peralta, J. E.; Ogliaro, F.; Bearpark, M. J.; Heyd, J. J.; Brothers, E. N.; Kudin, K. N.; Staroverov, V. N.; Keith, T. A.; Kobayashi, R.; Normand, J.; Raghavachari, K.; Rendell, A. P.; Burant, J. C.; Iyengar, S. S.; Tomasi, J.; Cossi, M.; Millam, J. M.; Klene, M.; Adamo, C.; Cammi, R.; Ochterski, J. W.; Martin, R. L.; Morokuma, K.; Farkas, O.; Foresman, J. B.; Fox, D. J. Gaussian 16 Rev. C.01, Wallingford, CT, 2016.

(S2) Zhao, Y.; Truhlar, D. G. The M06 Suite of Density Functionals for Main Group Thermochemistry, Thermochemical Kinetics, Noncovalent Interactions, Excited States, and Transition Elements: Two New Functionals and Systematic Testing of Four M06-Class Functionals and 12 Other functionals. Theor. Chem. Acc. 2008, 120, 215-241.

(S3) Scalmani, G.; Frisch, M. J. Continuous Surface Charge Polarizable Continuum Models of Solvation. I. General Formalism. J. Chem. Phys. 2010, 132, 114110.

(S4) Barone, V.; Cossi, M. Quantum Calculation of Molecular Energies and Energy Gradients in Solution by a Conductor Solvent Model. J. Phys. Chem. A 1998, 102, 1995-2001.

(S5) Cossi, M.; Rega, N.; Scalmani, G.; Barone, V. Energies, Structures, and Electronic Properties of Molecules in Solution with the C-PCM Solvation Model. J. Comput. Chem. 2003, 24, 669-681.

(S6) Garcia-Hartjes, J.; Dommerholt, J.; Wennekes, T.; van Delft, F. L.; Zuilhof, H. Electronic Effects versus Distortion Energies During Strain-Promoted Alkyne-Azide Cycloadditions: A Theoretical Tool to Predict Reaction Kinetics. Eur. J. Org. Chem. 2013, 2013, 3712-3720.

(S7) Escorihuela, J.; Das, A.; Looijen, W. J. E.; van Delft, F. L.; Aquino, A. J. A.; Lischka, H.; Zuilhof, H. Kinetics of the Strain-Promoted Oxidation-Controlled Cycloalkyne-1,2-Quinone Cycloaddition: Experimental and Theoretical Studies. J. Org. Chem. 2018, 83, 244-252.

(S8) Gold, B.; Dudley, G. B.; Alabugin, I. V. Moderating Strain without Sacrificing Reactivity: Design of Fast and Tunable Noncatalyzed Alkyne-Azide Cycloadditions via Stereoelectronically Controlled Transition State Stabilization. J. Am. Chem. Soc. 2013, 135, 1558-1569.

(S9) Bach, R. D. Ring Strain Energy in the Cyclooctyl System. The Effect of Strain Energy on [3 + 2] Cycloaddition Reactions with Azides. J. Am. Chem. Soc. 2009, 131, 5233-5243.

(S10) McGrath, N. A.; Raines, R. T. Diazo Compounds as Highly Tunable Reactants in 1,3-Dipolar Cycloaddition Reactions with Cycloalkynes. Chem. Sci. 2012, 3, 3237-3240.

(S11) Alexakos, P. D.; Wardrop, D. J. $N$-Morpholinomethyl-5-lithiotetrazole: A Reagent for the One-Pot Synthesis of 5-(1-Hydroxyalkyl)tetrazoles. J. Org. Chem. 2019, 84, 12430-12436. 
NMR Spectra (All compounds were dissolved in $\mathrm{CDCl}_{3}$ unless indicated otherwise.)

${ }^{1} \mathrm{H}$ and ${ }^{13} \mathrm{C}$ NMR Spectra of 4-((N-Tetrazolyl)methyl)morpholine (8)

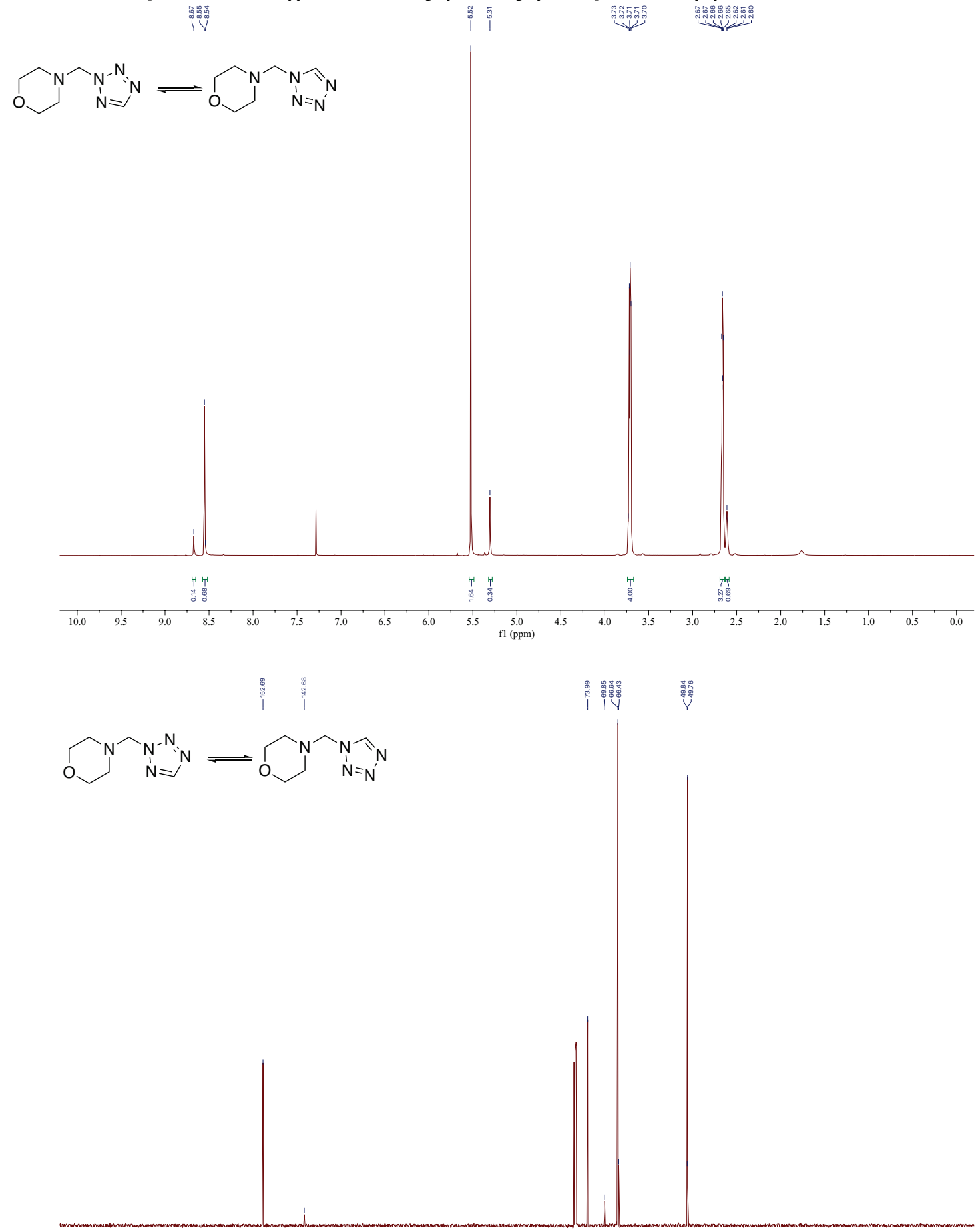


${ }^{1} \mathrm{H}$ and ${ }^{13} \mathrm{C}$ NMR Spectra of 8-Chloro-11-(1H-tetrazol-5-yl)-6,11-dihydro-5Hbenzo[5,6]cyclohepta[1,2-b]pyridin-11-ol (4)
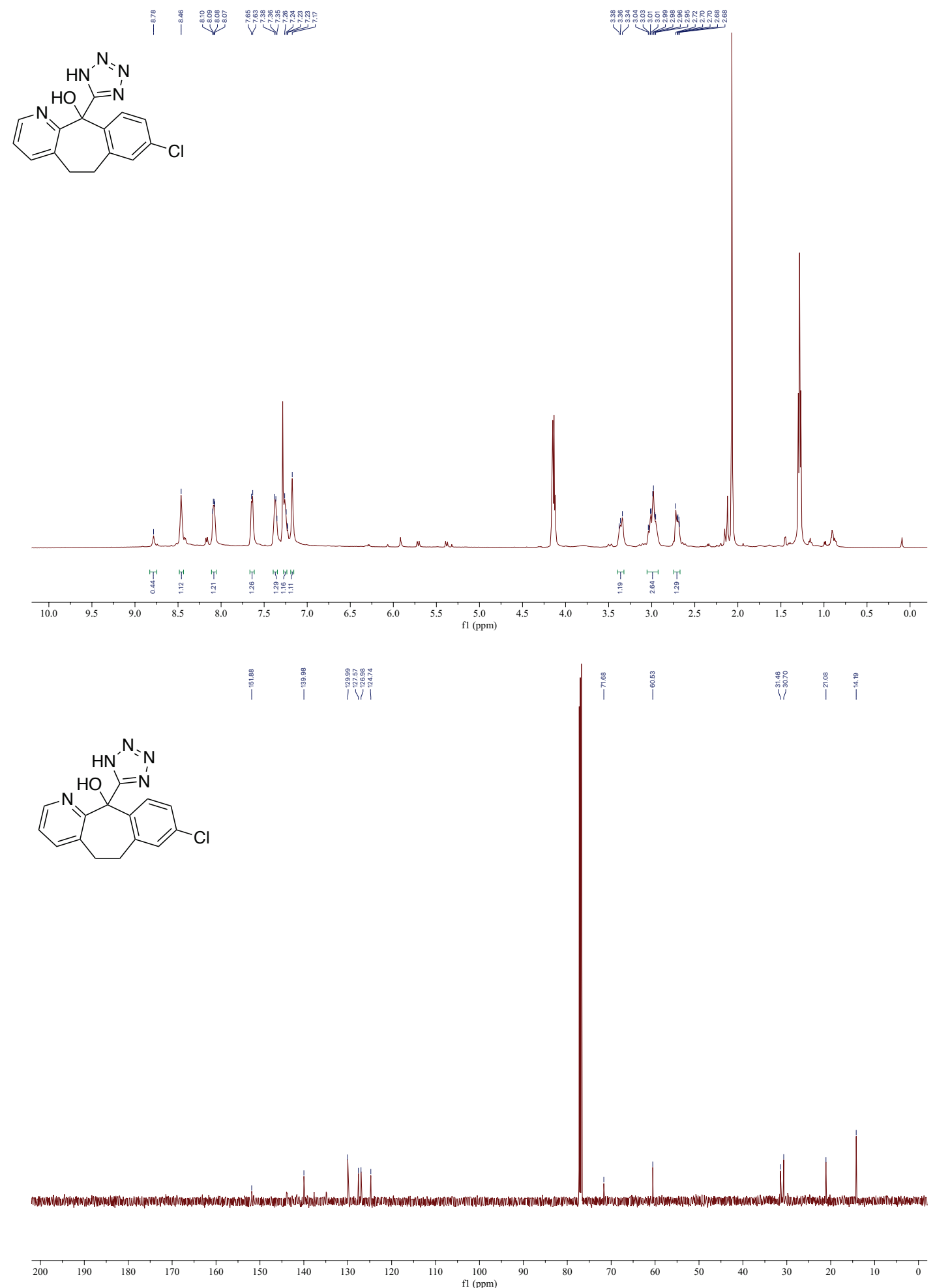
${ }^{1} \mathrm{H}$ and ${ }^{13} \mathrm{C}$ NMR Spectra of 2-Azabenzo-8-chlorobenzocyclooctyne (ABC)
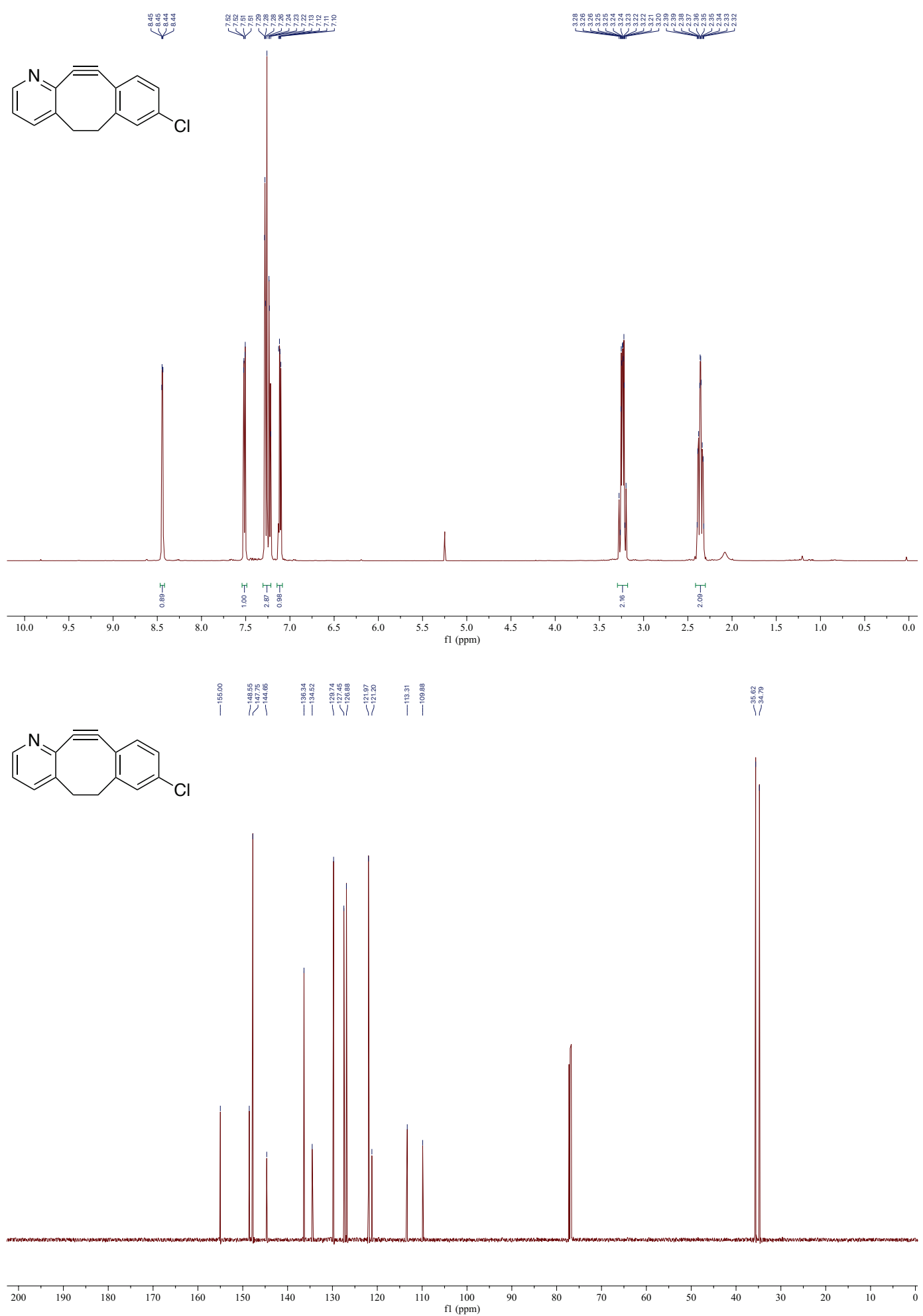
${ }^{1} \mathrm{H}$ NMR Spectrum of 2-Azido-N-benzylacetamide (5)

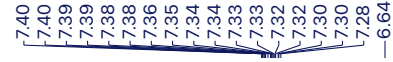<smiles>N#CCC(=O)NCc1ccccc1</smiles>

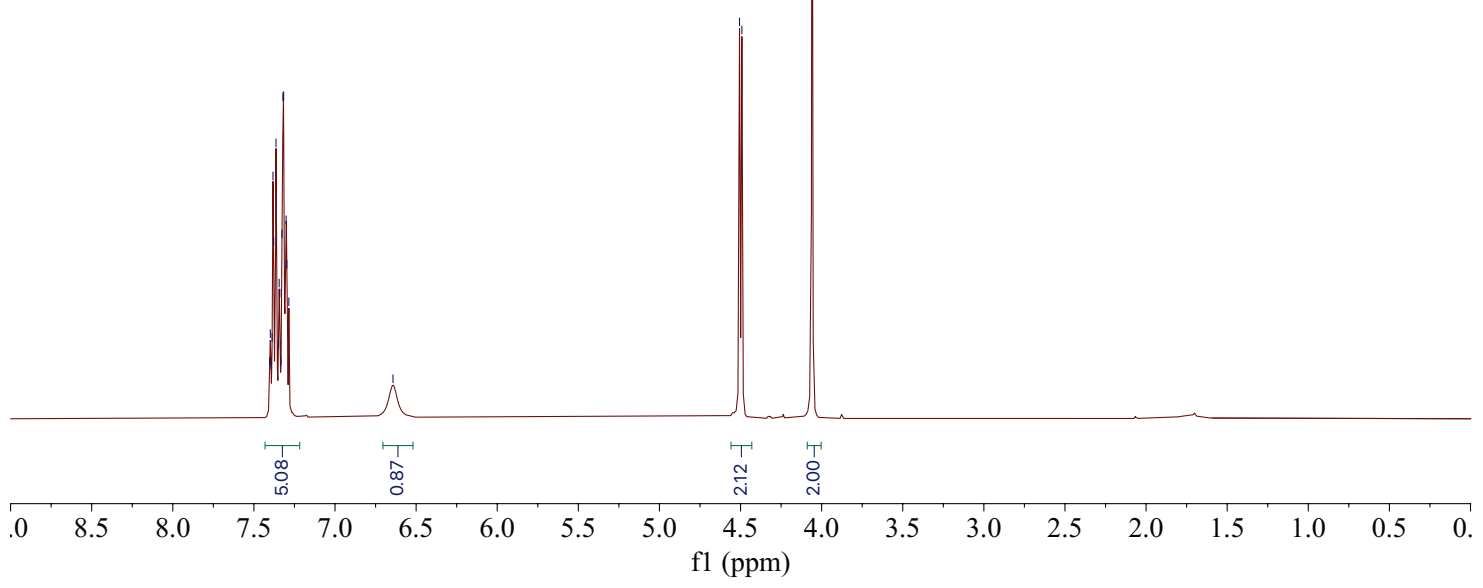

${ }^{1} \mathrm{H}$ NMR Spectrum of $\mathbf{N}$-Benzylacetamide

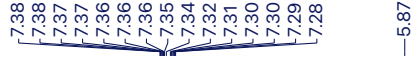<smiles>CC(=O)NCc1ccccc1</smiles>

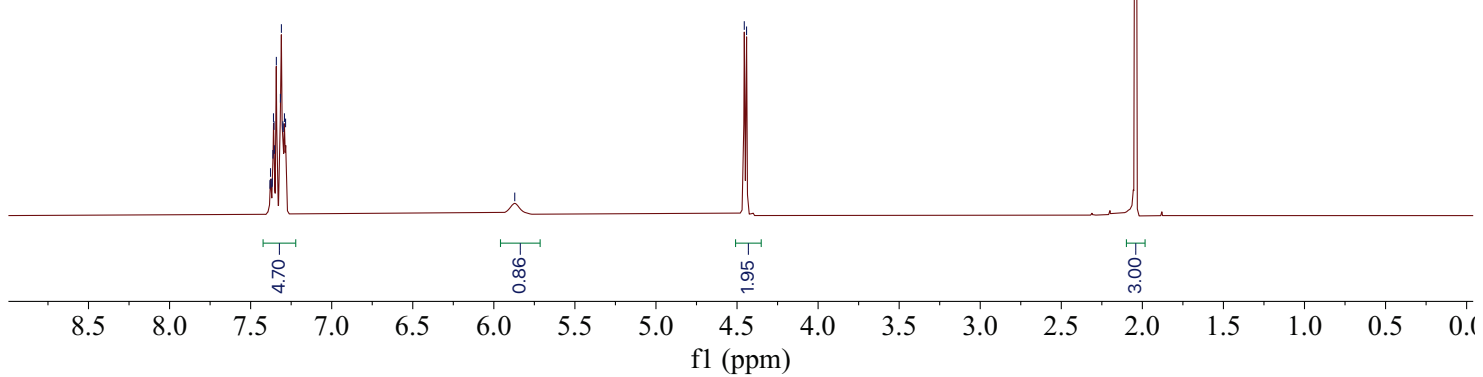


${ }^{1} \mathrm{H}$ and ${ }^{13} \mathrm{C}$ NMR Spectra of 5-(1H-Tetrazol-5-yl)-10,11-dihydro-5H-dibenzo[a,d][7]annulen-

5-ol (9). Both spectra were obtained in $\mathrm{CD}_{3} \mathrm{OD}$.

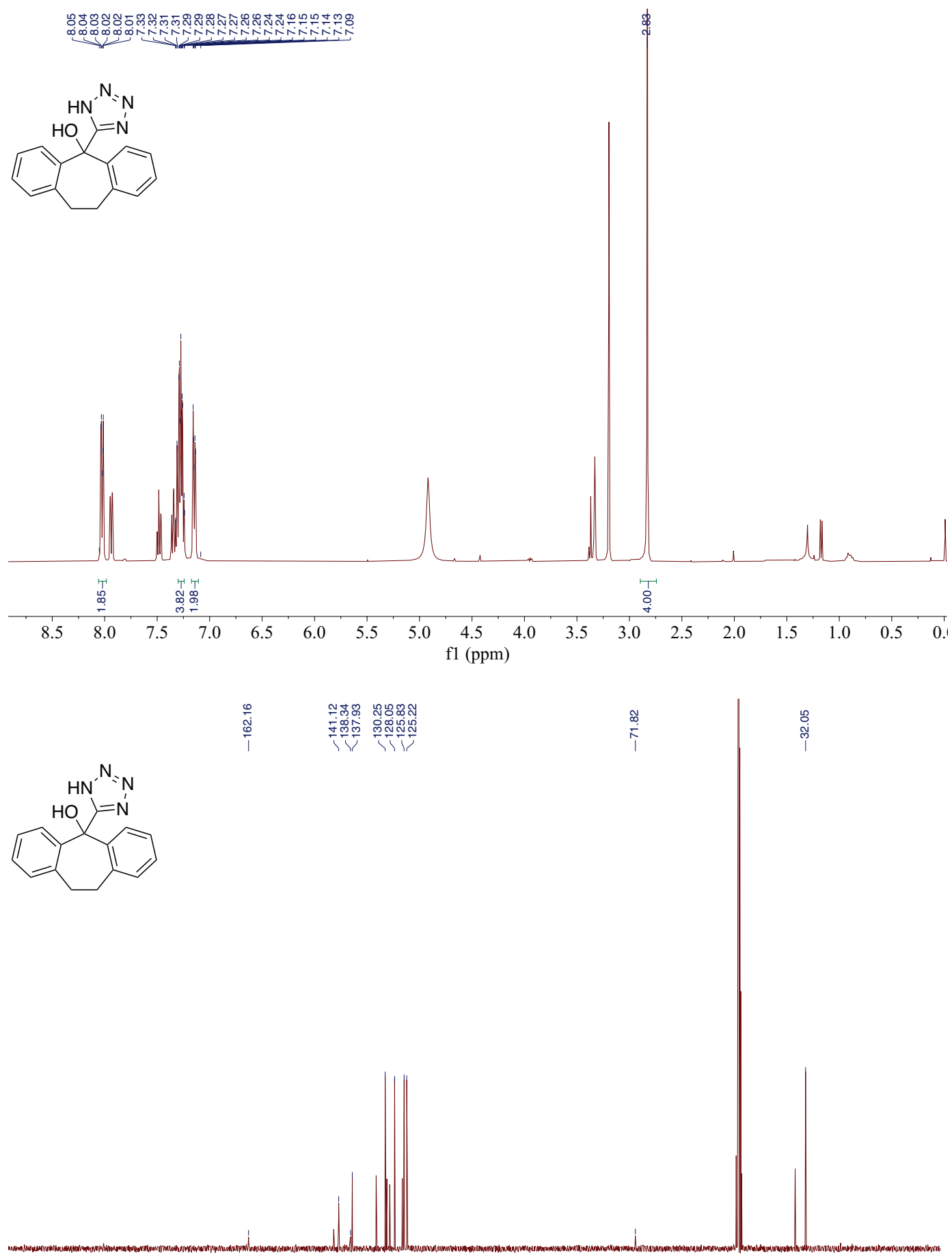

$\begin{array}{lllllllllllllllllllll}210 & 200 & 190 & 180 & 170 & 160 & 150 & 140 & 130 & 120 & 110 & 100 & 90 & 80 & 70 & 60 & 50 & 40 & 30 & 20 & 10\end{array}$ 


\section{${ }^{1} \mathrm{H}$ and ${ }^{13} \mathrm{C}$ NMR Spectra of Dibenzocyclooctyne (DIBO)}

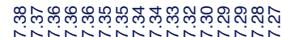

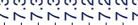

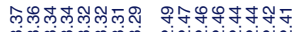

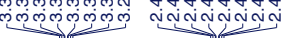

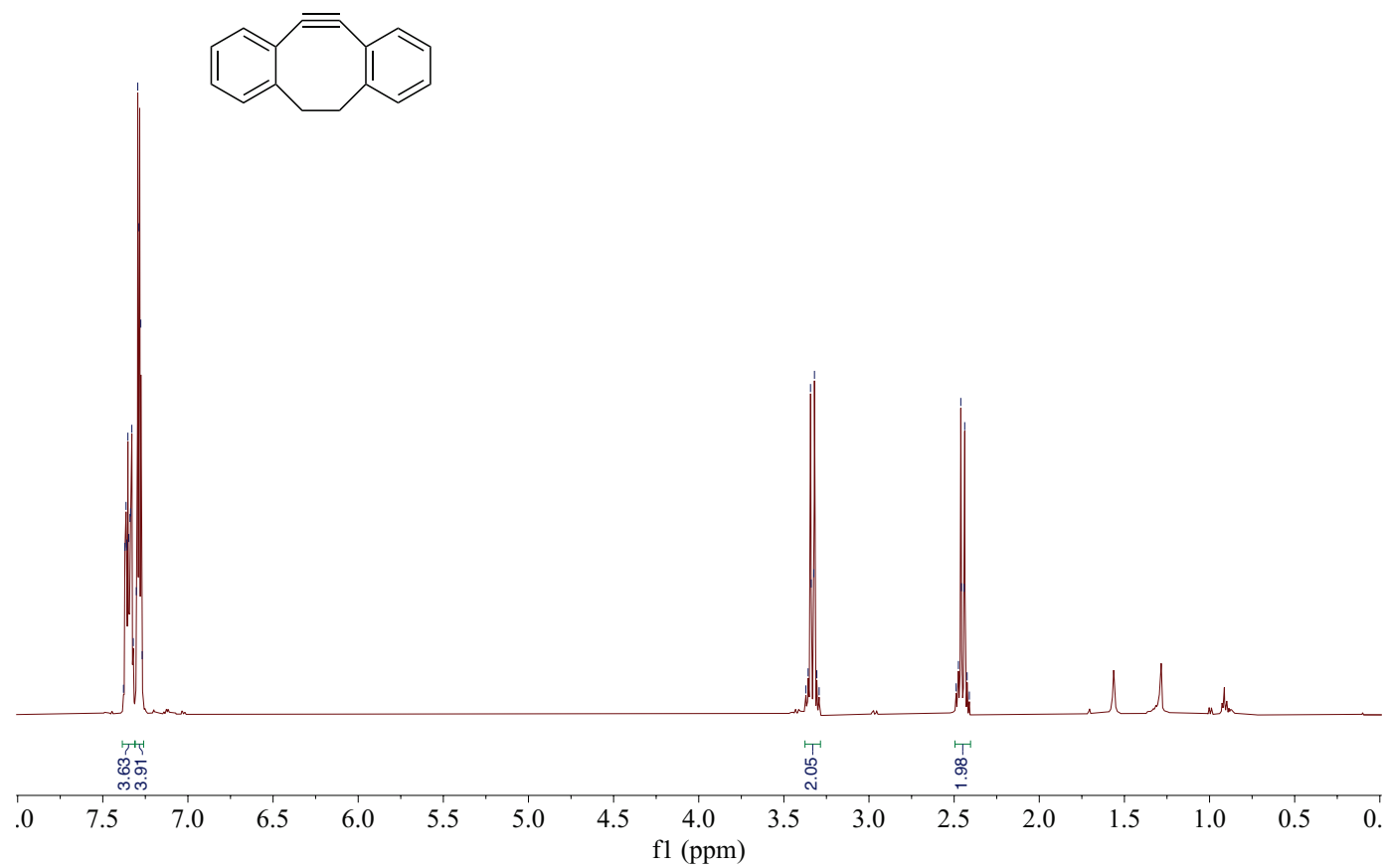

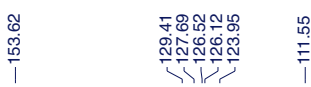
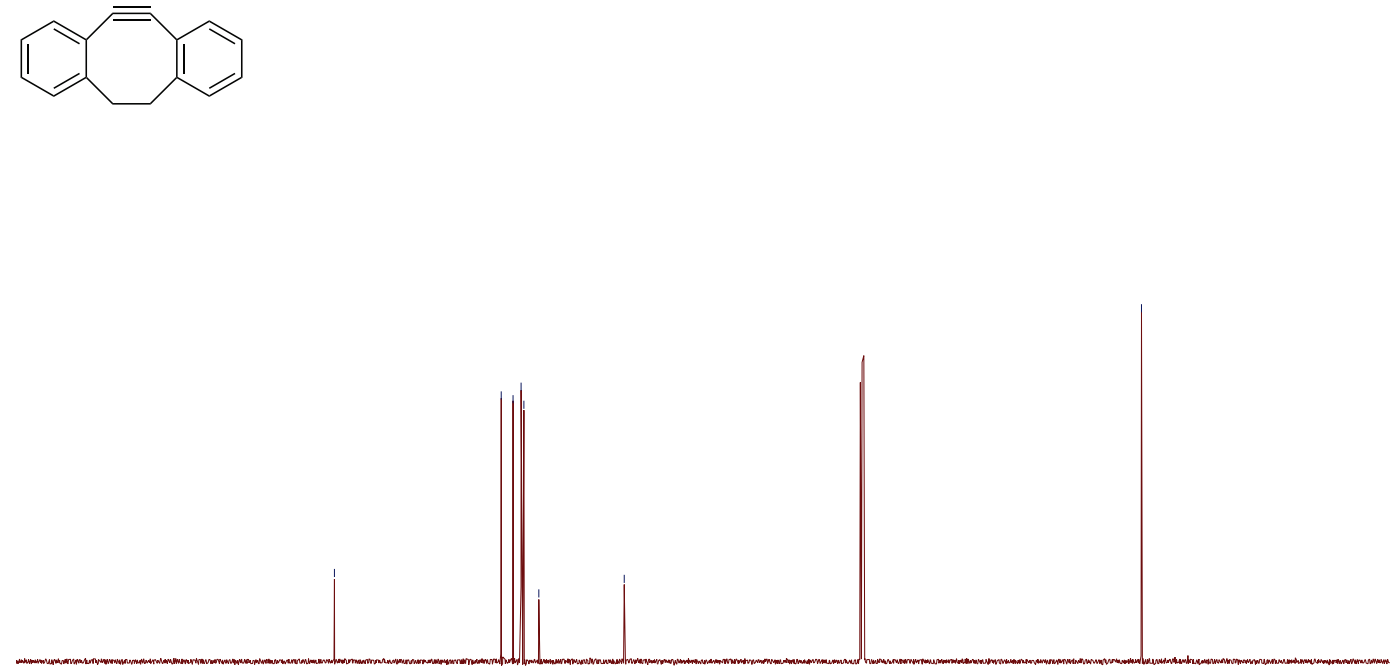

$\begin{array}{llllllllllllllllll}190 & 180 & 170 & 160 & 150 & 140 & 130 & 120 & \begin{array}{c}110 \\ \mathrm{fl}(\mathrm{ppm})\end{array} & \begin{array}{c}100 \\ (\mathrm{ppm})\end{array} & 80 & 70 & 60 & 50 & 40 & 30 & 20 & 10\end{array}$ 
${ }^{1} \mathrm{H}$ and ${ }^{13} \mathrm{C}$ NMR Spectra of 2-Azido-N-methyl-N-(phenylmethyl)acetamide (11)

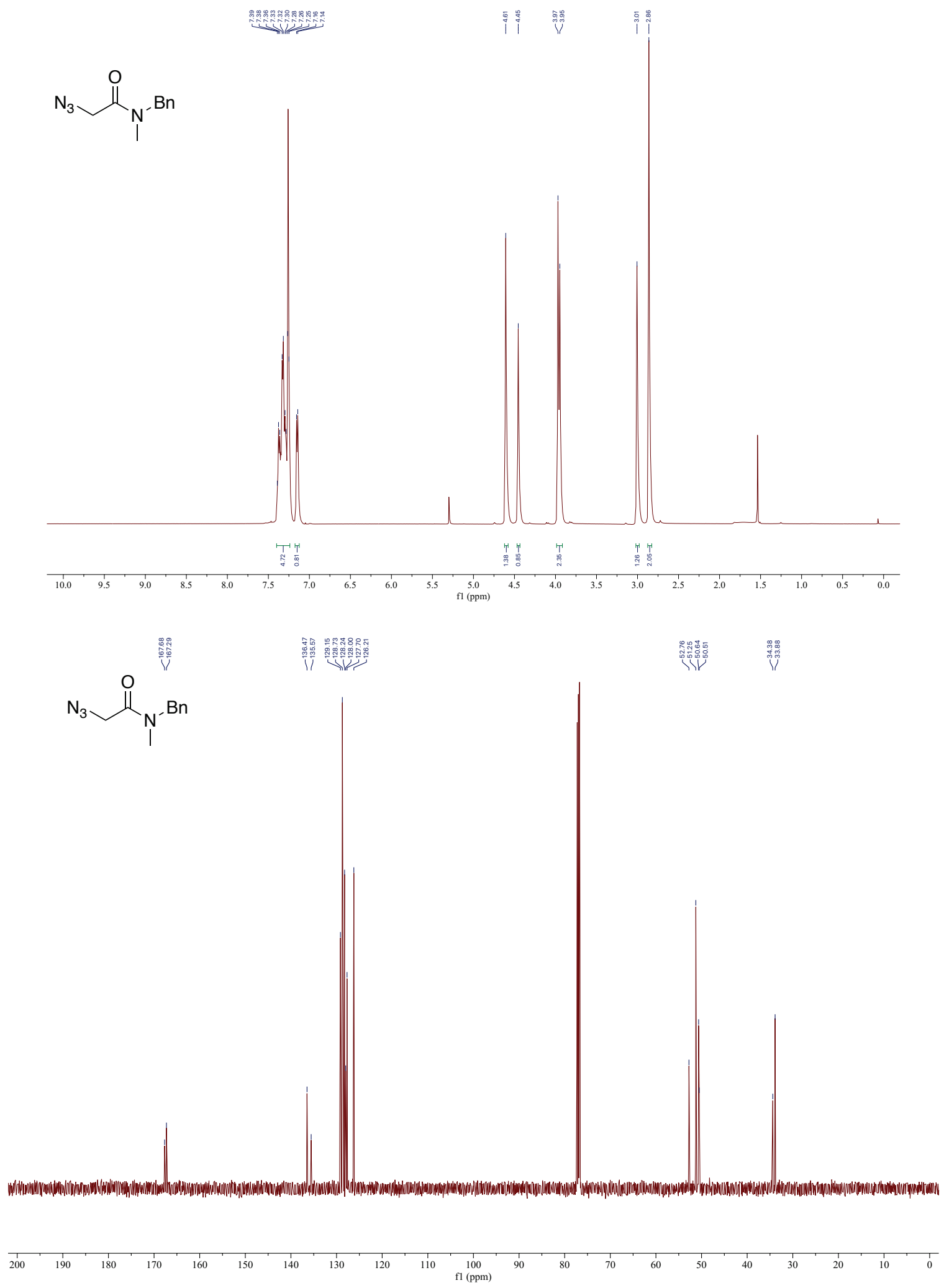


${ }^{1} \mathrm{H}$ and ${ }^{13} \mathrm{C}$ NMR Spectra of 2-Diazo-N-methyl- $N$-(phenylmethyl)acetamide (12)
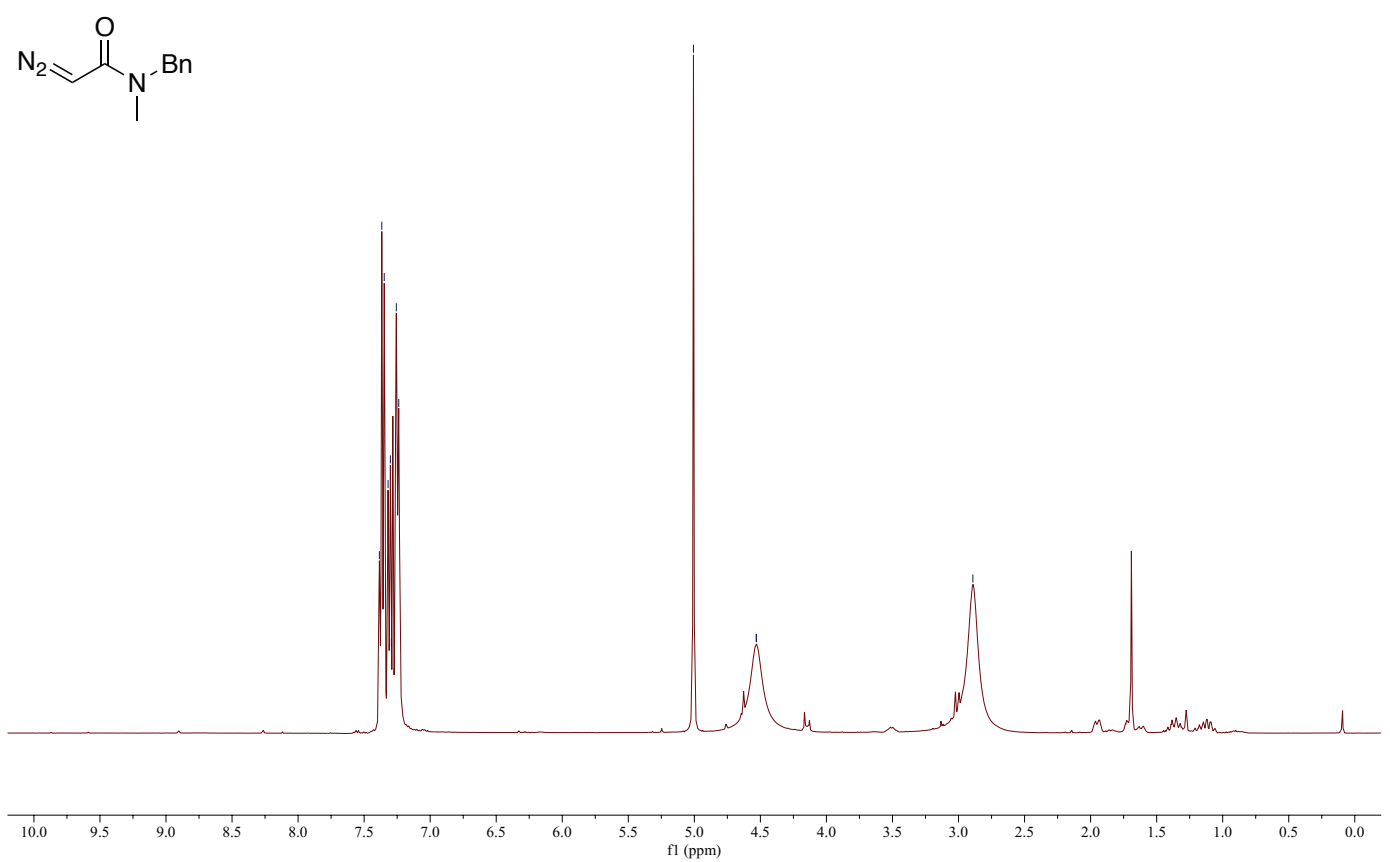

$\mathrm{N}_{2} \geqslant \stackrel{\mathrm{l}}{\mathrm{O}}_{\mathrm{N}^{-B n}}$
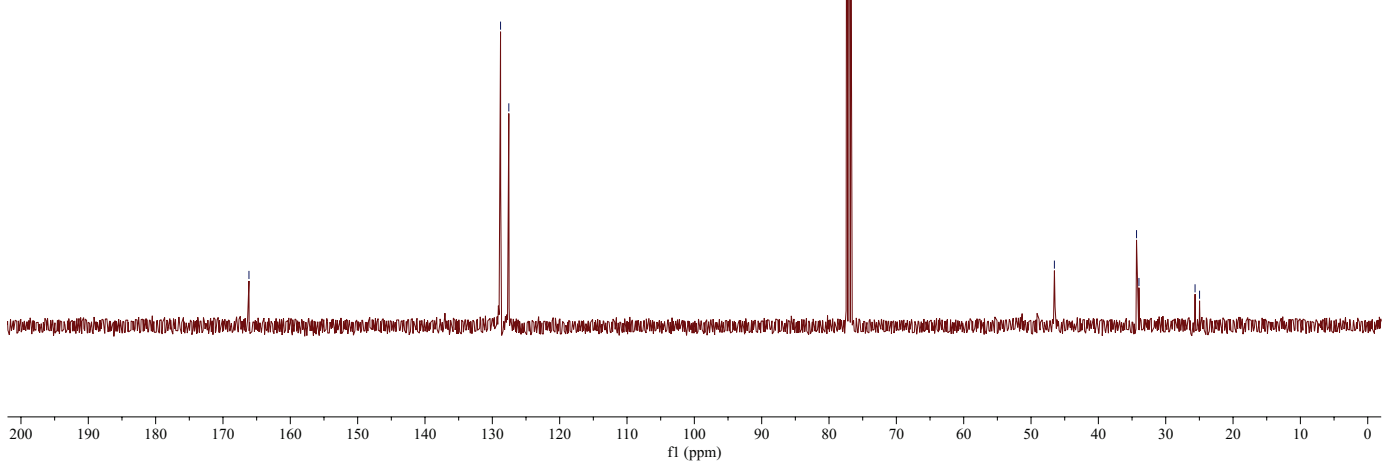
${ }^{1} \mathrm{H}$ and ${ }^{13} \mathrm{C}$ NMR Spectra of ABC-2-diazo-N-benzylacetamide Cycloadduct (13)
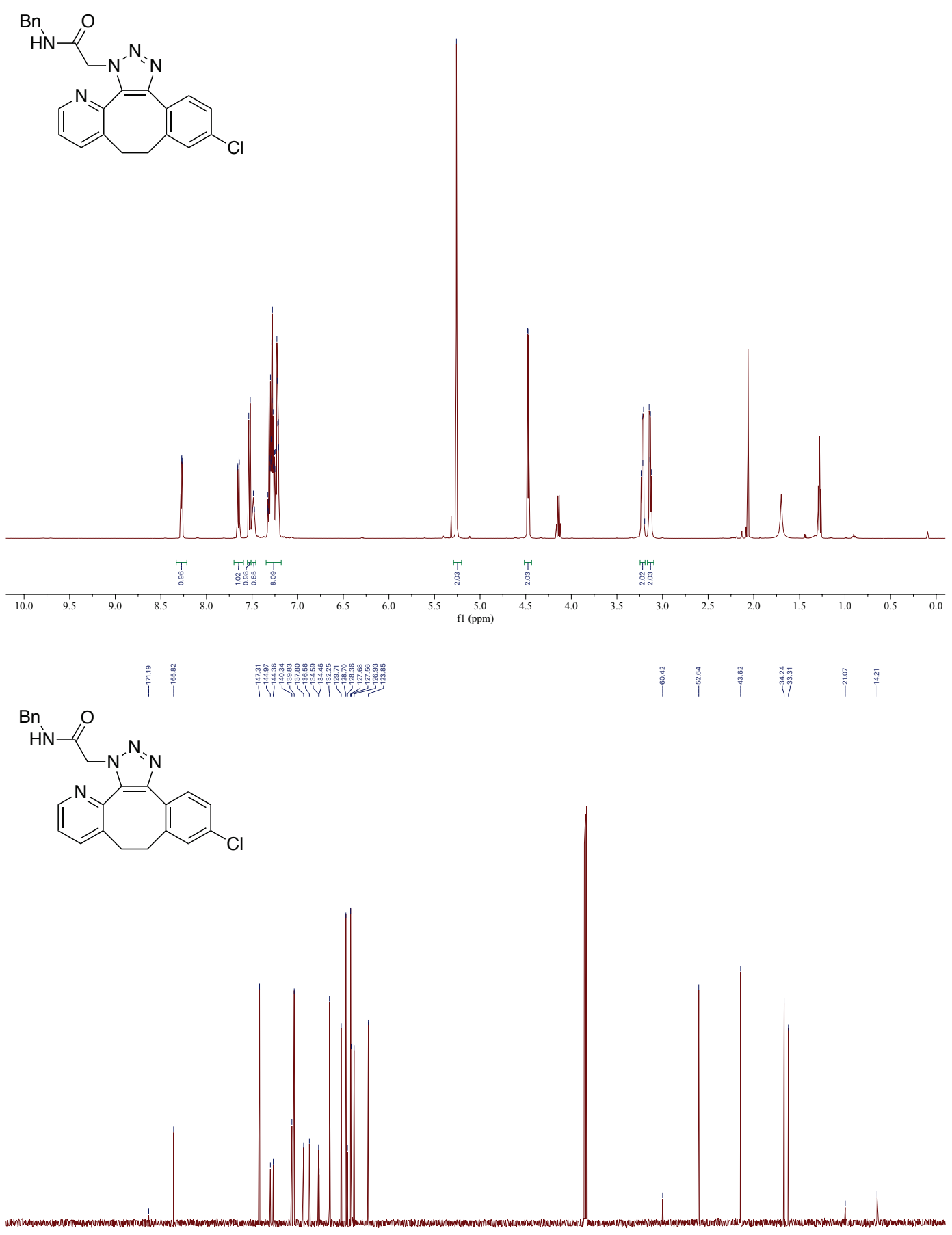

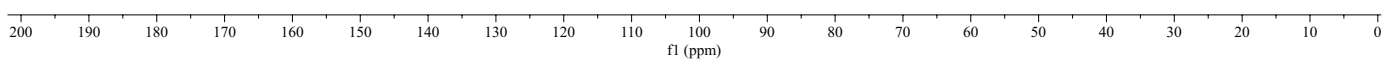


${ }^{1} \mathrm{H}$ and ${ }^{13} \mathrm{C}$ NMR Spectra of ABC-2-diazo-N-benzylacetamide Cycloadduct (14)
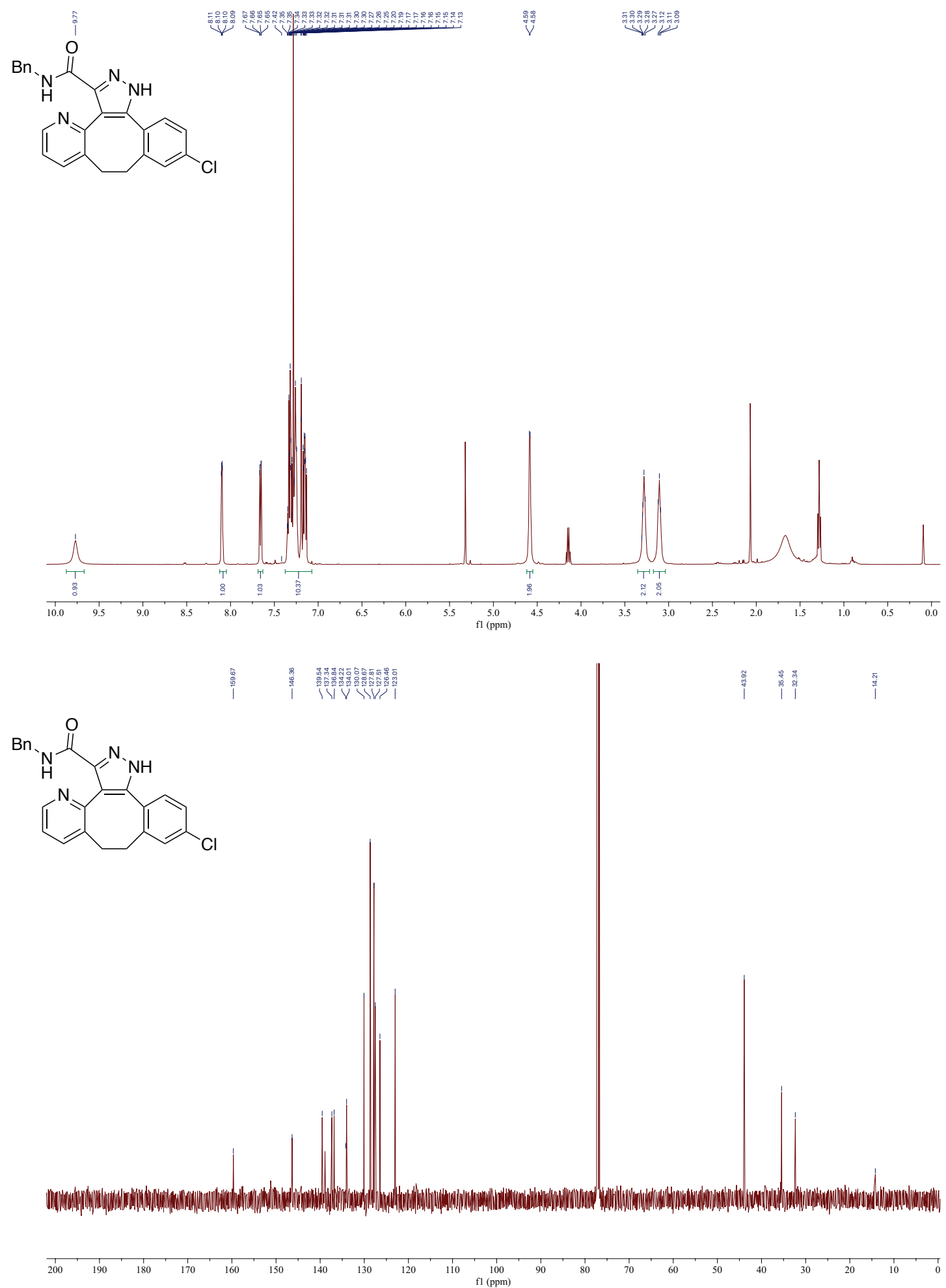
${ }^{1} \mathrm{H}$ and ${ }^{13} \mathrm{C}$ NMR Spectra of $\mathrm{ABC}-2$-azido-N-methyl-N-(phenylmethyl)acetamide Cycloadduct (15)
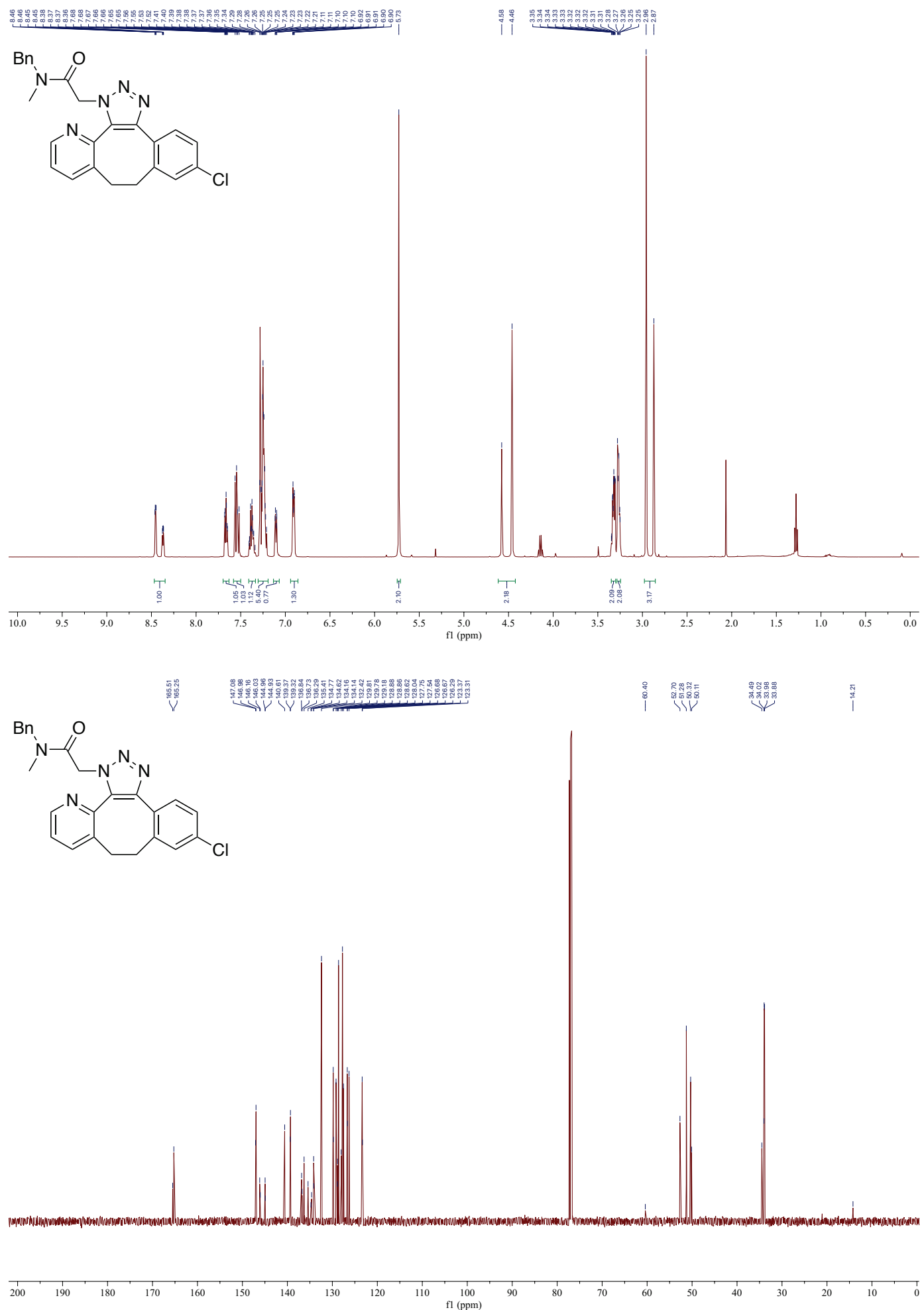
${ }^{1} \mathrm{H}$ and ${ }^{13} \mathrm{C}$ NMR Spectra of $\mathrm{ABC}-2$-diazo-N-methyl-N-(phenylmethyl)acetamide Cycloadduct (16)
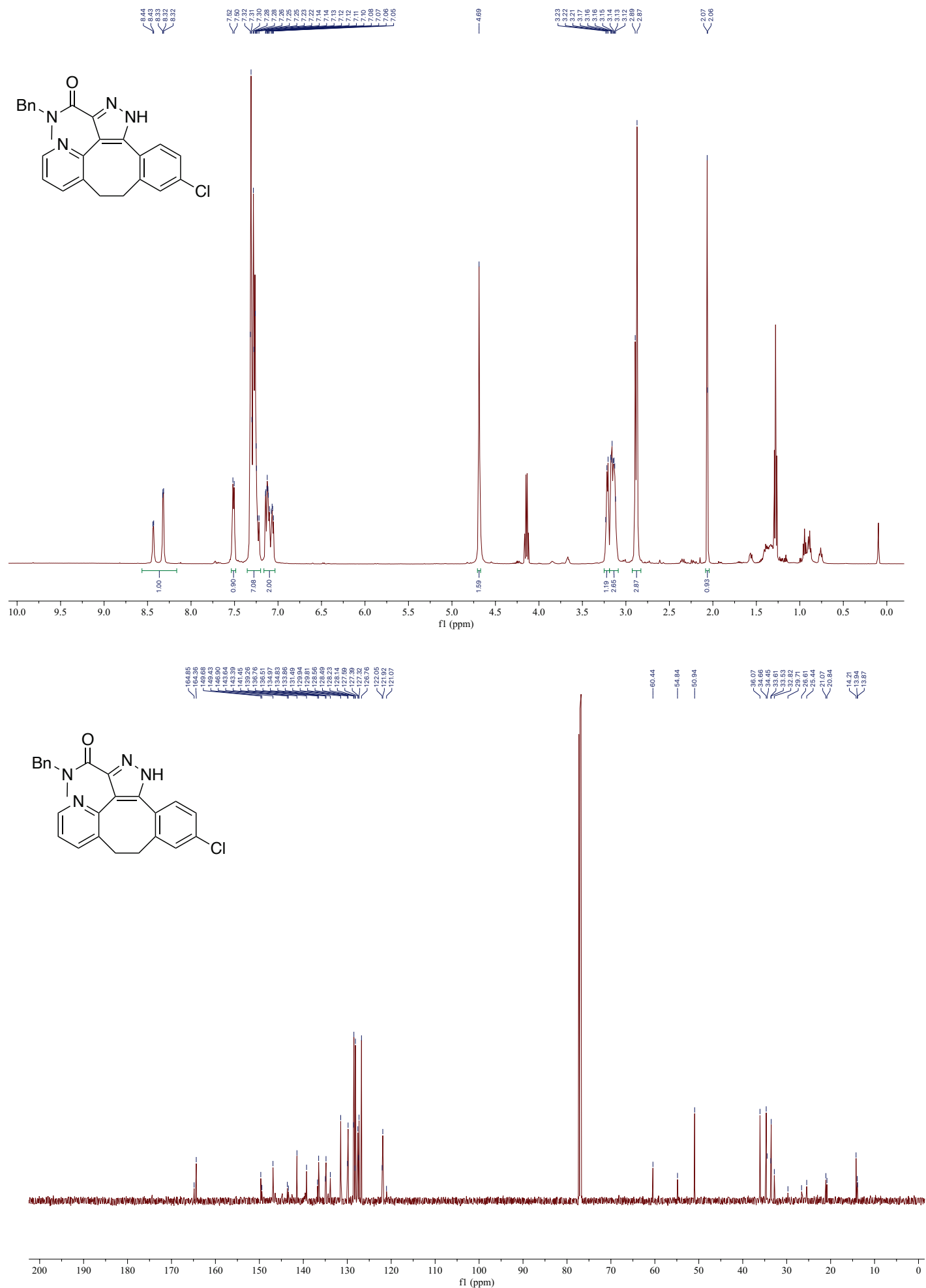
${ }^{1} \mathrm{H}$ and ${ }^{13} \mathrm{C}$ NMR Spectra of ABC-benzyl Diazoacetate Cycloadduct (17)

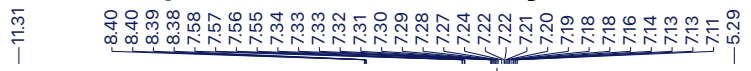<smiles></smiles>
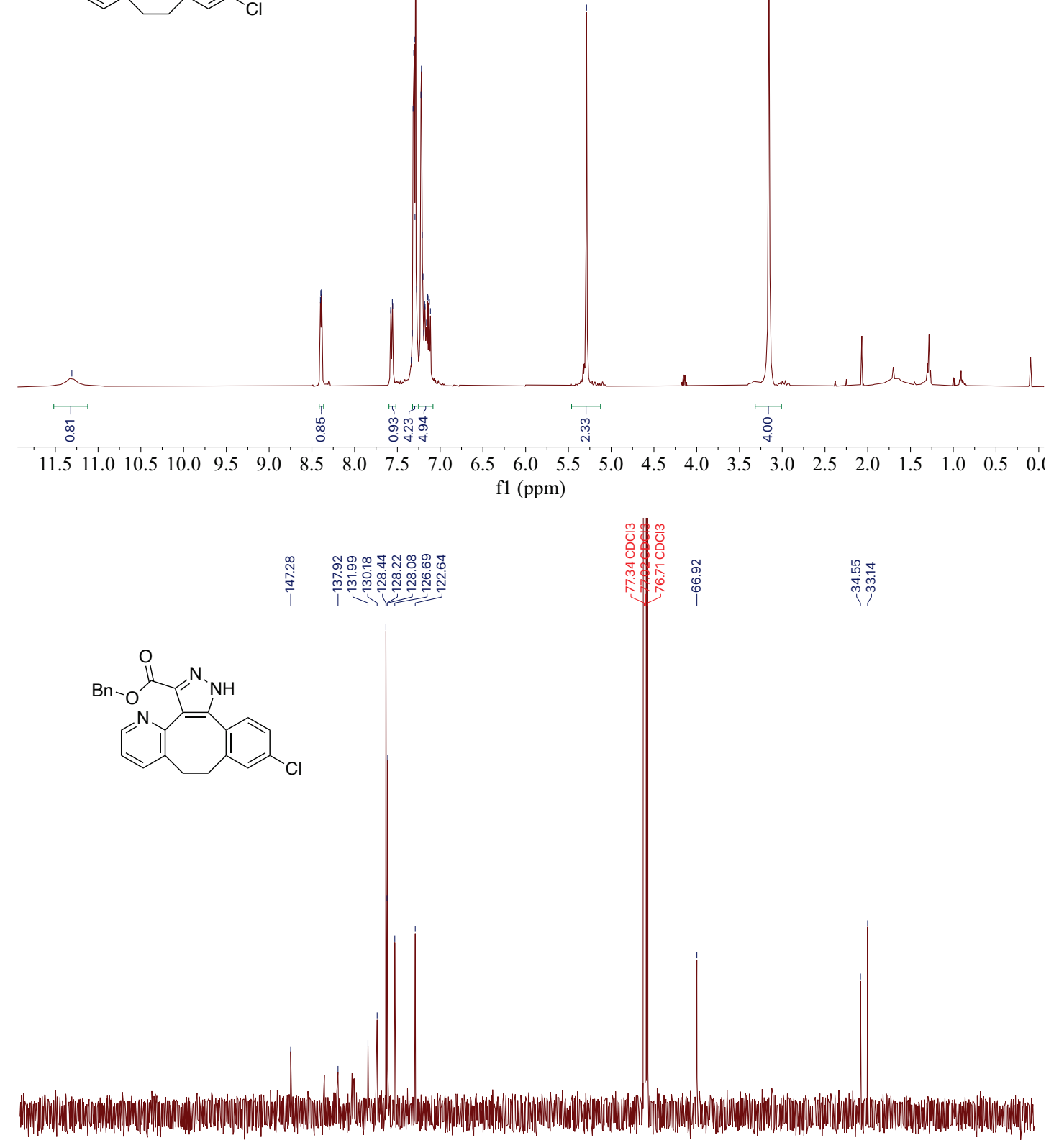

\begin{tabular}{llllllllllllllllllll}
\hline 00 & 190 & 180 & 170 & 160 & 150 & 140 & 130 & 120 & 110 & 100 & 90 & 80 & 70 & 60 & 50 & 40 & 30 & 20 & 10
\end{tabular} 
${ }^{1} \mathrm{H}$ and ${ }^{13} \mathrm{C}$ NMR Spectra of DIBO-2-azido-N-benzylacetamide Cycloadduct (18)
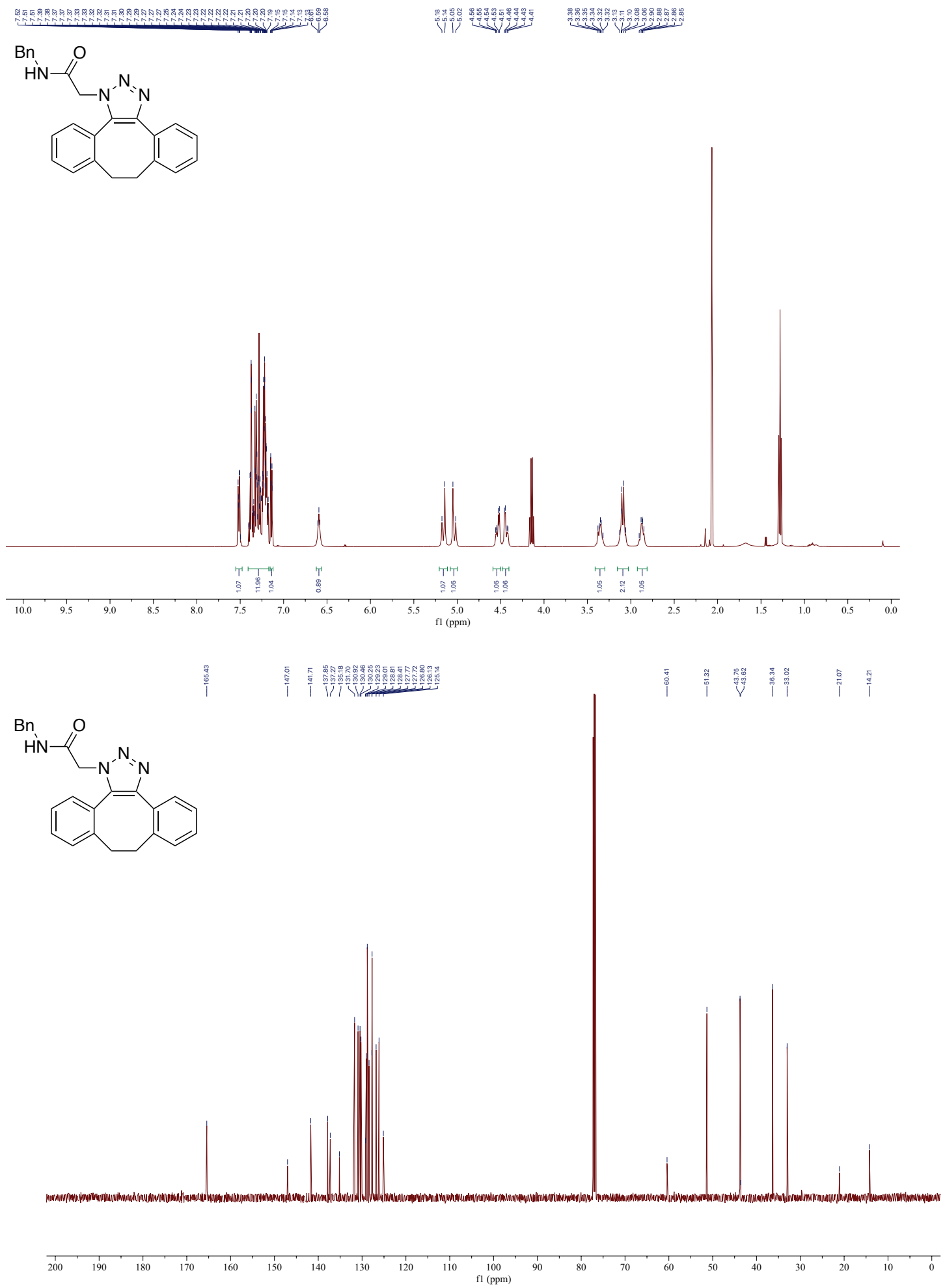
${ }^{1} \mathrm{H}$ and ${ }^{13} \mathrm{C}$ NMR Spectra of DIBO-2-diazo-N-benzylacetamide Cycloadduct (19)
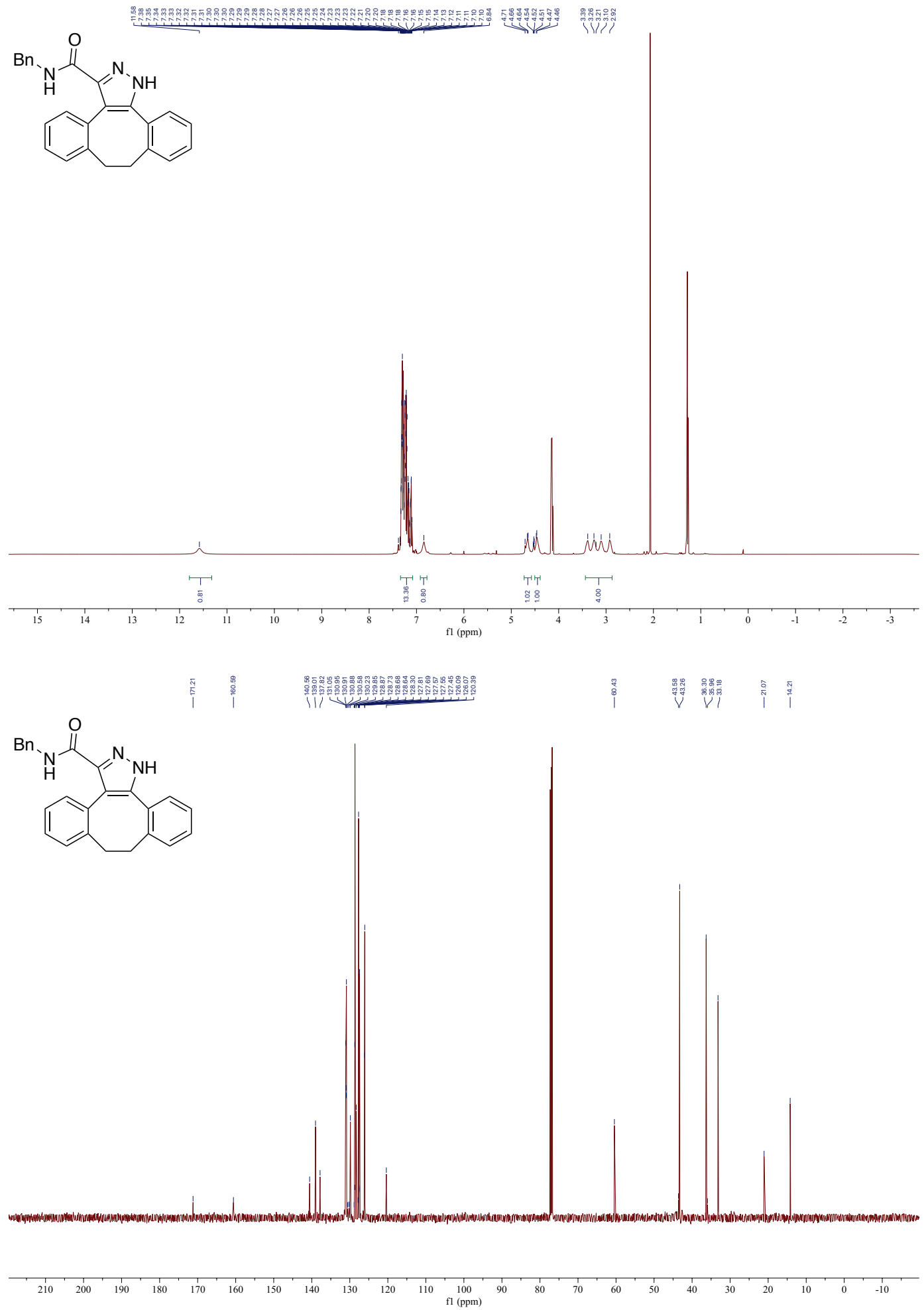


\section{${ }^{1} \mathrm{H}$ and ${ }^{13} \mathrm{C}$ NMR Spectra of DIBO-benzyl Diazoacetate Cycloadduct (20)}

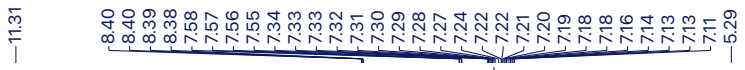
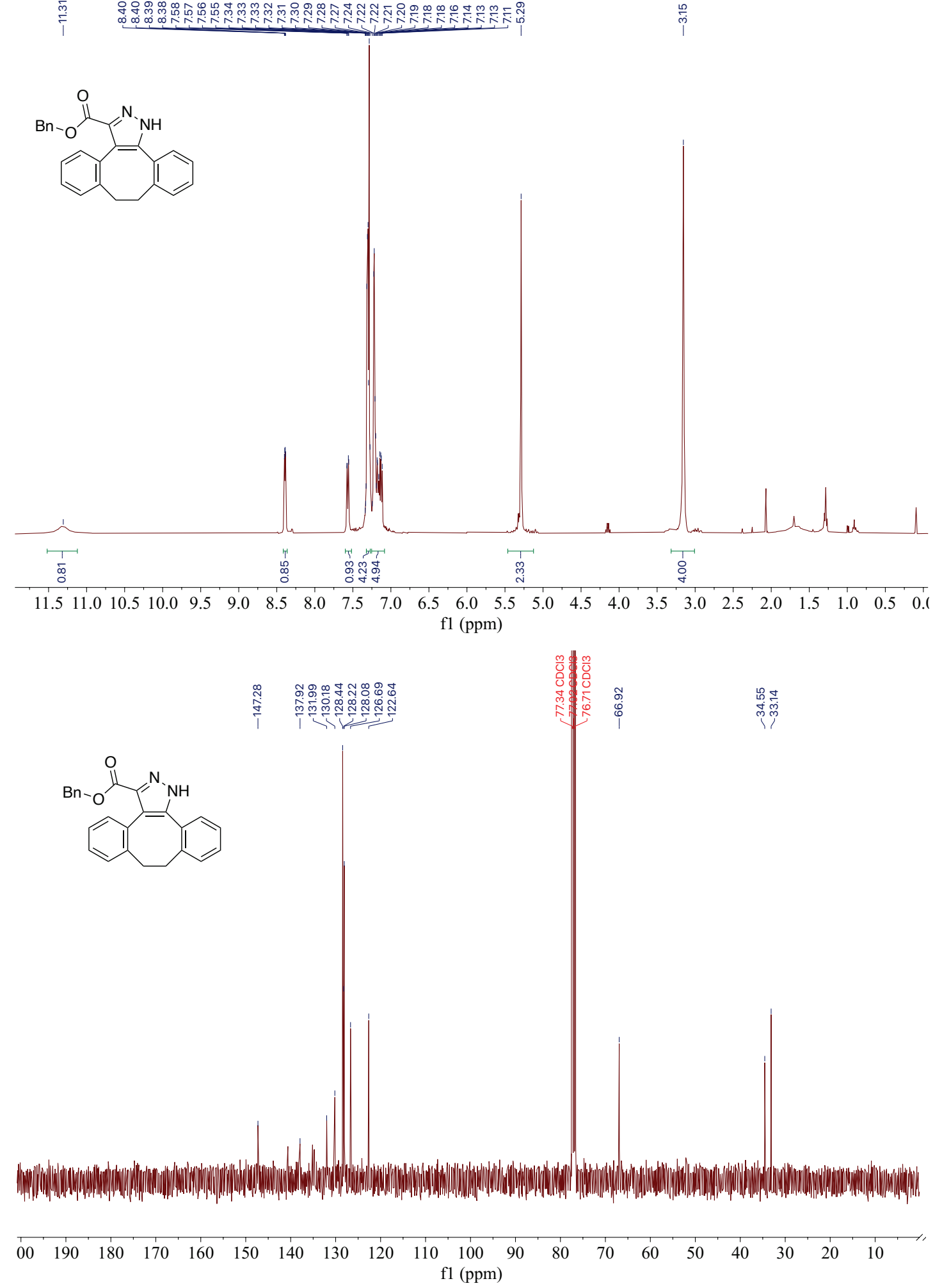